\title{
Trabajo y mujeres privadas de la libertad: trabajando al margen del derecho laboral ${ }^{*}$
}

DOI: https://doi.org/10.18046/recs.iEspecial.3252

\author{
Work and Women Prisoners: Working at the Margins \\ of Labor Law
}

Astrid Sánchez-Mejía ${ }^{* *}$

Pontificia Universidad Javeriana (Bogotá, Colombia)

Juliana Morad ${ }^{* * *}$

Pontificia Universidad Javeriana (Bogotá, Colombia)

\footnotetext{
* En este artículo se analizan datos del proyecto de investigación "Mujeres y prisión en Colombia", realizado por la Pontificia Universidad Javeriana, el Comité Internacional de la Cruz Roja y el Centro de Investigación y Docencia Económicas de México (CIDE) (Sánchez-Mejía; Rodríguez-Cely; Fondevila; Morad-Acero, 2018). En este proyecto, la investigadora principal fue Astrid Sánchez-Mejía y los coinvestigadores fueron Leonardo Rodríguez-Cely, Gustavo Fondevila y Juliana Morad. Esta investigación se llevó a cabo entre julio de 2017 y diciembre de 2018, con la financiación de la Pontificia Universidad Javeriana y el Comité Internacional de la Cruz Roja. Artículo de investigación recibido el 13.11.18 y aceptado el 13.05.19.

** Profesora asociada del Departamento de Filosofía e Historia del Derecho y directora del Doctorado en Ciencias Jurídicas de la Facultad de Ciencias Jurídicas de la Pontificia Universidad Javeriana (Colombia). Correo electrónico: astrid. sanchez@javeriana.edu.co ORCID: https://orcid.org/oooo-0oo3-0852-3116

*** Profesora instructora del Departamento de Derecho Laboral de la Facultad de Ciencias Jurídicas de la Pontificia Universidad Javeriana (Colombia). Correo electrónico: jmorad@javeriana.edu.co ORCID: https://orcid.org/ooooooo1-8834-4825
} 


\section{Cómo citar/How to cite}

Sánchez-Mejía, Astrid; Morad, Juliana (2019). Trabajo y mujeres privadas de la libertad: trabajando al margen del derecho laboral. Revista CS, núm. especial, 199-239.

https://doi.org/10.18046/recs.iEspecial.3252 
A partir de una investigación basada en metodologías mixtas, este artículo muestra que el perfil socioeconómico de la mayoría de mujeres privadas de la libertad en Colombia se caracteriza por una situación de marginalidad múltiple, debido a la intersección entre género y bajo estatus socioeconómico. Asimismo, explora las necesidades específicas y experiencias de estas mujeres en relación con el trabajo, teniendo en cuenta su perfil y su rol de cuidadoras principales. El análisis se divide en tres momentos: antes de la detención, en la prisión, y después de retornar a la comunidad, donde se evidencia que la prisión refuerza la desigualdad atada a su género y bajo estatus socioeconómico. Este artículo hace énfasis en que es crucial ofrecer programas, intervenciones y servicios que tengan en cuenta el perfil de las mujeres y su situación de marginalidad múltiple, con el fin de mejorar su efectividad. Adicionalmente, sugiere repensar el alcance del derecho laboral en relación con el trabajo penitenciario.

PALABRAS CLAVE:

mujeres privadas de la libertad, historia laboral, trabajo penitenciario

Based on a mixed-methodology research, this article shows that the socio-economic profile of the majority of women deprived of their liberty in Colombia is characterized by a multiple marginality situation, due to the connection between gender and low socio-economic status. Likewise, this text explores the specific needs and the experiences of these women in relation to work, by considering their profile and role as primary caregivers. The analysis is divided into three moments: before detention, in prison, and after returning to the community where it is evident that prison strengthens inequality linked to their gender and low socio-economic status. These social-economic vulnerability conditions include precarious employment. It is fundamental to offer programs, interventions, and services that consider women's profile and their situation, particularly, training in prison for a job that will be productive and useful when released. Additionally, it is important to rethink the scope of labor law in relation to prison work.

\section{KEYWORDS:}

Women Deprived of their Liberty, Labor History, Prison Work 



\section{Introducción}

Entre 1991 y 2018, la tasa de mujeres en prisión por 100 ooo habitantes mujeres, en Colombia, aumentó $219 \%$, de 9,9 en 1991, a 31,5 en junio de $2018^{1}$. El número de mujeres privadas de la libertad en los centros penitenciarios del Instituto Nacional Penitenciario y Carcelario (INPEC) pasó de 1500 en 1991, a 7944 en junio de 2018. A pesar de este aumento acelerado, la población penitenciaria está conformada, mayoritariamente, por hombres; a junio de 2018, los hombres representaban el 93,3 \% de la población privada de la libertad (PPL) a cargo del INPEC. El mayor número de hombres oculta las necesidades específicas de las mujeres en el sistema penal y el penitenciario ${ }^{2}$. Aunque las mujeres comparten problemas de los hombres privados de la libertad, como el hacinamiento y la falta de recursos, ellas tienen circunstancias de vida específicas asociadas al género; por ejemplo, las experiencias de discriminación por la jerarquía de género y el rol de ser las principales cuidadoras de sus hijos (Casas-Becerra, 2010; Covington; Bloom, 2003).

Las diferencias de género tienen implicaciones en la trayectoria hacia el delito, los tipos de delitos cometidos, la práctica de la justicia penal y el impacto de la prisión (Chesney-Lind; Pasko, 2013; Covington; Bloom, 2003). El género también interactúa con otros ejes de desventaja social, como la raza y la clase en el contexto de la prisión (Crenshaw, 1991). Las mujeres que pertenecen a clases diferentes suelen tener experiencias disímiles. Asimismo, mujeres y hombres de la misma clase pueden compartir características, pero la experiencia de las mujeres es diferente porque el género implica especificidades.

Así las cosas, las políticas públicas relacionadas con el sistema penal y el penitenciario deben atender las diferencias y necesidades específicas de las mujeres por dos razones. En primer lugar, ignorar su contexto de vida y sus necesidades en las políticas actuales las ha convertido en una fuente de discriminación, de intensificación del castigo o de sufrimiento desproporcionado (Ariza; Iturralde, 2015; Bloom; Owen; Covington, 2003; Casas-Becerra, 2010). Lo anterior se debe a que las prisiones agravan las formas de opresión y discriminación de las mujeres que tienen a cargo dependientes y que se encuentran en situación de pobreza y marginalidad, tanto durante la reclusión como después de quedar en libertad (Ariza; Iturralde, 2015).

En segundo lugar, las diferencias entre hombres y mujeres afectan los resultados de los programas, servicios e intervenciones en el marco del sistema penal. Enfrentar

1. Tasas de encarcelamiento calculadas con base en los datos del promedio de la población penitenciaria por año del Instituto Nacional Penitenciario y Carcelario (INPEC) y las proyecciones de la población colombiana por año del Departamento Administrativo Nacional de Estadística (DANE).

2. Ver Ariza e Iturralde (2015), Bloom, Owen y Covington (2003), y Casas-Becerra (2010). 
los factores asociados a la trayectoria del delito en las vidas de las mujeres, a través de políticas y programas sensibles al género, es fundamental para mejorar los resultados en todas las fases de la justicia penal. Este tipo de políticas pueden contribuir a generar impactos positivos a corto y largo plazo para el sistema, la comunidad, las mujeres infractoras y sus familias (Covington; Bloom, 2003).

Para el diseño de políticas públicas y programas más eficaces, es necesario contar con datos sobre el perfil, las características sociodemográficas y los patrones de historia personal de las mujeres. A pesar de ello, no existen muchos datos disponibles en Colombia sobre estos elementos ${ }^{3}$.

Con el fin de contribuir a llenar este vacío, este artículo presenta datos cualitativos y cuantitativos sobre las experiencias y necesidades específicas de las mujeres privadas de la libertad en relación con el trabajo, teniendo en cuenta su perfil y su rol de cuidadoras principales. Las preguntas que se exploran a lo largo del texto son las siguientes: ¿cuál es el perfil de las mujeres privadas de la libertad?, ¿cuál era la historia laboral de las internas antes de ser detenidas?, ¿cuáles son las limitaciones de los programas laborales en los centros penitenciarios?, ¿cuáles son las expectativas frente al mercado laboral que tienen estas mujeres al retornar a la comunidad?

Este artículo interviene en los debates sobre trabajo y mujeres privadas de la libertad en Colombia de tres maneras. En primer lugar, presenta datos sobre el perfil, las necesidades específicas y las experiencias de las mujeres privadas de la libertad, mostrando que ellas experimentan un continuo de marginalidad múltiple, debido a la intersección entre género y bajo nivel socioeconómico. En segundo lugar, explora algunas limitaciones de los programas o actividades laborales en los centros penitenciarios, mostrando la necesidad de que su diseño atienda a las condiciones específicas de las mujeres infractoras para aumentar su efectividad. En tercer lugar, analiza el rol y alcance del derecho laboral frente al trabajo penitenciario ${ }^{4}$,

3. Los datos del INPEC sobre mujeres en las prisiones se limitan a algunas variables como edad, nivel educativo, participación en los programas en los centros penitenciarios, entre otras. Hay algunos estudios sobre los perfiles criminales y las experiencias de las mujeres en las cárceles colombianas; la mayoría de los cuales tienen algunas limitaciones, ya que muchos se enfocaban en un solo centro penitenciario, solo recolectaron datos cualitativos o se basaron en los datos limitados del INPEC (Aristizábal; Ríos-García; Del Pozo-Serrano, 2016; Ariza-Higuera; Ángel-Botero, 2015; Ariza; Iturralde, 2015; 2017; Briceño-Donn, 2006; Caicedo, 2017; Céspedes; Rojas; Rojas; Ramírez, 2012; Cruz; Martínez-Osorio; Chaparro-González; Uprimny-Yepes; Chaparro-Hernández, 2016; Del Pozo-Serrano; Martínez-Idárraga, 2015; López-Barbosa; Castro-Jiménez; Gamboa-Delgado; Vera-Cala, 2009; Ramos, 2003; Uprimny; Guzmán, 2010).

4. Existe un cuerpo de literatura sobre trabajo y derecho laboral que ha explorado la cuestión de quién es reconocido como trabajador y quién queda afuera. Algunos autores han propuesto la necesidad de ampliar el alcance del concepto de trabajador y del derecho laboral para incluir actividades tradicionalmente excluidas. Por ejemplo, la literatura feminista ha enfatizado la importancia de insertar el trabajo de cuidado y doméstico en el dominio del derecho laboral (Albin, 2012; Busby, 2011; Fudge, 2014; Silbaugh, 
mostrando su papel al construir identidades y establecer límites en relación con las mujeres privadas de la libertad y sus trabajos. El Código Sustantivo del Trabajo fija la identidad de trabajador, pero las experiencias de trabajo de muchas de las mujeres encuestadas (antes, durante y después de la prisión) no están representadas por esta idea. Este texto también muestra los efectos negativos que tiene la falta de aplicación de las leyes laborales frente a los trabajos desempeñados por muchas mujeres en los centros penitenciarios, e invita a repensar el alcance del derecho laboral en el contexto de la prisión.

La investigación a través de la que se recolectaron los datos analizados en este texto incorporó metodologías mixtas de investigación empírica, las cuales incluyeron datos cuantitativos y cualitativos. Se aplicó una encuesta (EPMPC) a 587 internos y 536 internas en siete centros penitenciarios del país en 2017. Adicionalmente, se realizaron 12 entrevistas semiestructuradas a actores clave, quienes fueron elegidos usando el método "bola de nieve". También se analizaron los datos estadísticos oficiales del INPEC (Sánchez-Mejía et al., 2018)5.

El presente artículo se divide en cuatro partes: la primera se enfoca en el perfil de las mujeres privadas de la libertad; la segunda analiza algunas limitaciones de las actividades laborales en los centros penitenciarios y de la regulación del trabajo penitenciario; la tercera parte estudia las expectativas laborales de las mujeres para el momento de retornar a la comunidad; y la cuarta presenta algunas conclusiones.

\section{Perfil de las mujeres privadas de la libertad antes de la detención}

En esta sección, se explora el perfil de las mujeres privadas de la libertad antes de la detención, teniendo en cuenta dos elementos: los perfiles socioeconómico y delictivo. Entender el perfil y algunos patrones de la historia personal de estas mujeres es clave para: i) identificar los motivos y factores asociados a sus conductas

1996). Asimismo, algunos autores han argumentado que el trabajo en prisión también debe ser interpretado como trabajo dentro del mercado y sujeto a las mismas condiciones del libre; es decir, el alcance del derecho laboral se debería expandir para regularlo (Clark; Parker, 1974; Zatz, 2009).

5. Para la Encuesta del Proyecto Mujeres y Prisión en Colombia (EPMPC), la selección de la muestra se dividió en dos etapas: i) selección de una cuota de establecimientos penitenciarios por regional; $\mathrm{y}$ ii) selección aleatoria de las personas a encuestar en cada centro penitenciario. Los centros penitenciarios seleccionados por regional fueron: Regional Central: Buen Pastor y La Picota (al realizar el trabajo de campo se cambió la segunda por Cómbita, debido a que La Picota y La Modelo estaban en cuarentena); Regional Occidente: Jamundí; Regional Norte: Montería; Regional Oriente: Cúcuta; Regional Noroeste: Pedregal; y Regional Viejo Caldas: Picaleña. 
delictivas (Ariza; Iturralde, 2015); ii) analizar el impacto que puede tener la prisión en ellas y sus familias (Ariza; Iturralde, 2015); iii) abordar las realidades y necesidades de las mujeres infractoras a través de políticas y programas de la justicia penal (Covington; Bloom, 2003); y iv) mejorar los resultados del sistema de justicia penal, especialmente en términos de reducir las probabilidades de reincidencia, en tanto se podrían diseñar programas, intervenciones y servicios que ataquen los factores asociados a las conductas delictivas (Bloom et al., 2003; Covington; Bloom, 2003).

\section{Perfil socioeconómico}

Los datos de la Encuesta del proyecto "Mujeres y prisión en Colombia” (EPMPC) sugieren que el perfil de la mayoría de las mujeres privadas de la libertad, antes de su detención, se caracterizaba por la precariedad económica, la condición de cabeza de familia y la informalidad laboral. Estos tres fenómenos han sido considerados causa y efecto -a la vez- de la exclusión y extrema desigualdad (Rico de Alonso, 2006).

\section{Precariedad económica}

Las mujeres son más proclives a estar en situación de pobreza en Colombia, según indica el índice de feminidad de hogares pobres (Observatorio de Igualdad de Género de América Latina y el Caribe [OIG], 2017) ${ }^{6}$. En 2014, por cada 100 hombres viviendo en hogares pobres había 118,4 mujeres. Esta situación se agudiza en hogares con mayor presencia de niños (Comisión Económica para América Latina y el Caribe [CEPAL], s. f.).

En este contexto, los datos de la EPMPC sugieren que un alto porcentaje de las mujeres encuestadas se encontraba en situación de vulnerabilidad y precariedad económica antes de la detención, teniendo en cuenta tres aspectos: su nivel educativo cruzado con la edad, el estrato del inmueble que habitaban y los ingresos mensuales de su hogar.

El nivel educativo cruzado con la edad puede ser un proxy de nivel socioeconómico (American Psychological Association [APA], 2007). Esta variable se usa para medir la condición de pobreza, teniendo en cuenta la incidencia de esta frente a la acumulación de capital humano (Centro de Estudios sobre Desarrollo Económico [CEDE], 2011).

6. Índice de feminidad de hogares pobres, 2014. Este índice compara el porcentaje de mujeres y hombres pobres de 20 a 59 años y muestra las disparidades en la incidencia de la pobreza (indigencia) entre hombres y mujeres. Un valor superior a 100 indica que la pobreza afecta en mayor grado a las mujeres. 
Con base en los datos sobre nivel educativo y edad de las mujeres encuestadas, se puede afirmar que la mayoría de ellas tiene un nivel socioeconómico bajo. El 56,7 \% se encuentra entre 25 y 39 años (Figura 1), y solo el 17,2 \% tuvo acceso a estudios de educación superior (Figura 2). Cabe resaltar que la mayoría de las mujeres se encuentra en una edad activa laboralmente y en la que se debería haber alcanzado la educación superior.

\section{\begin{tabular}{l|l} 
FIGURA 1 & Edad de las mujeres (años al momento de la encuesta)
\end{tabular}}

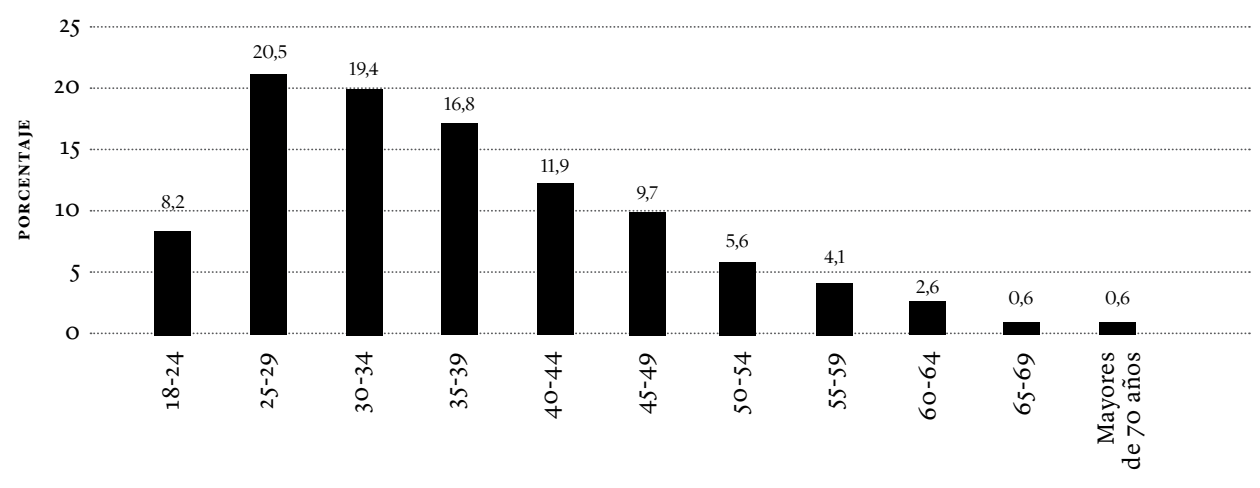

\begin{tabular}{l|l} 
FIGURA 2 & Nivel educativo alcanzado
\end{tabular}

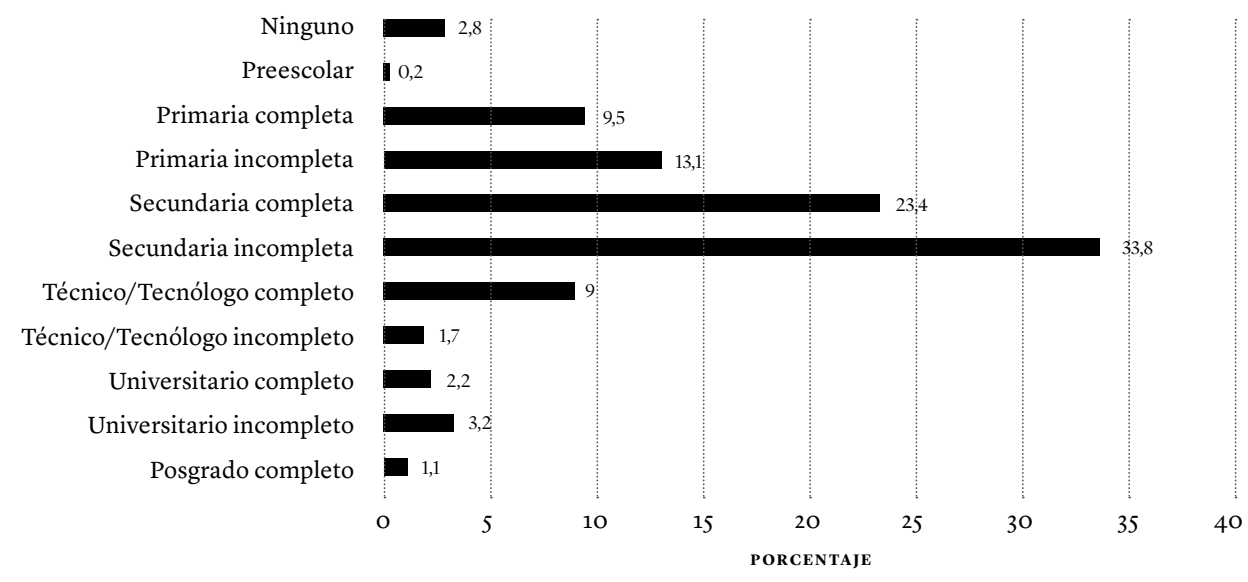


La educación es uno de los aspectos fundamentales del estatus, ya que los niveles de educación más altos están asociados con mejores resultados económicos y con mayores recursos sociales. Un nivel educativo alto aumenta las probabilidades de conseguir empleo (APA, 2007), así como la posibilidad de acceder a un mercado formal (Quejada-Pérez; Yánez-Contreras; Cano-Hernández, 2014). En consecuencia, los bajos niveles educativos de las mujeres encuestadas pueden limitar su acceso al mercado laboral y sus posibilidades de optar por un empleo bien remunerado y con condiciones favorables.

Otra medición aproximada de las condiciones socioeconómicas de las mujeres entrevistadas en la EPMPC es el estrato del inmueble en el que residían antes de la detención. La Figura 3 muestra que el 66,9 \% de las mujeres encuestadas en la EPMPC residía en inmuebles pertenecientes a estratos 1 y 2.

\begin{tabular}{|l|l|}
\hline FIGURA 3 & $\begin{array}{l}\text { Estrato socioeconómico del inmueble que habitaba antes de su última } \\
\text { detención }\end{array}$ \\
\hline
\end{tabular}

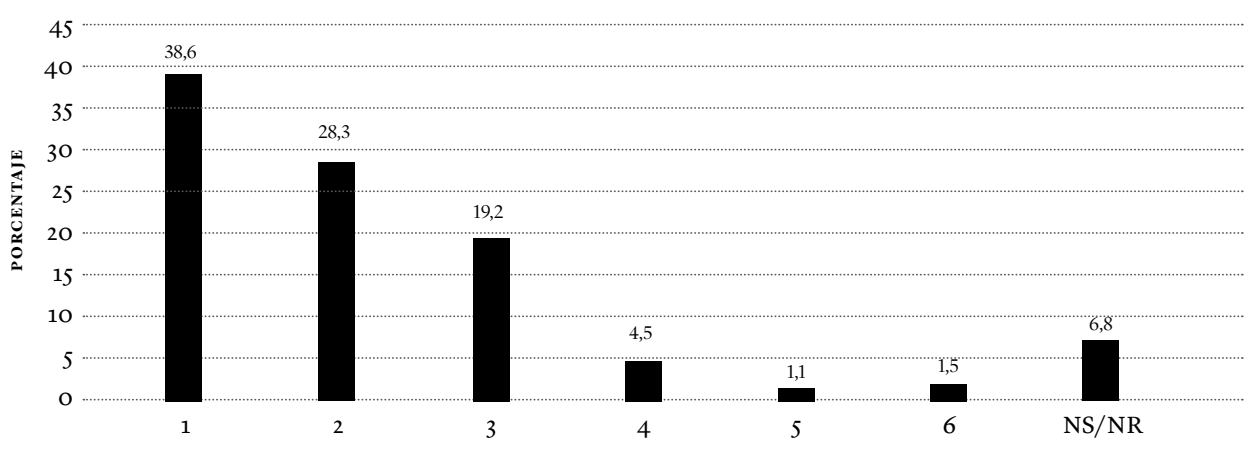

Fuente: encuesta proyecto "Mujeres y prisión en Colombia". N= $=531$

Los ingresos mensuales del hogar antes de la detención también son un indicador de las condiciones socioeconómicas de las mujeres entrevistadas; estos eran inferiores a un salario mínimo legal mensual (s. m. l. m. v.) en el 43,5\% de los casos (Figura 4).

En síntesis, el nivel educativo alcanzado, los ingresos mensuales del hogar y el estrato socioeconómico del inmueble que habitaban antes de la última detención permiten afirmar que un alto porcentaje de las mujeres encuestadas se encontraban en situación de precariedad económica. Dicha situación afectaba su seguridad y autonomía económica. 
FIGURA 4 Ingresos mensuales del hogar antes de la última detención

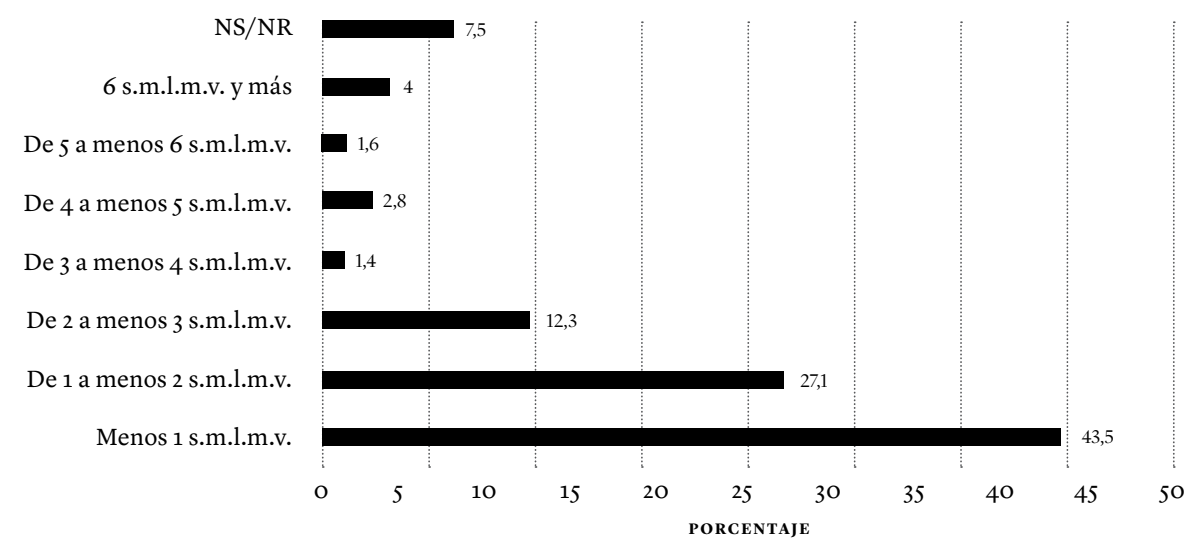

Fuente: encuesta proyecto "Mujeres y prisión en Colombia". N=506

\section{Mujeres cabeza de familia}

En cuanto a la situación de conyugalidad de las mujeres encuestadas en la EPMPC, es de resaltar que la mayoría no están unidas: son solteras $(56,6 \%)$ y separadas o divorciadas (6,6\%) (Figura 5).

El $75 \%$ de las mujeres encuestadas era cabeza de familia antes de la detención, es decir, ejercían la jefatura femenina de hogar y tenían bajo su cargo en forma permanente a sus hijos u otros dependientes. El porcentaje de mujeres privadas de la

\begin{tabular}{l|l} 
FIGURA 5 & Situación de conyugalidad de las mujeres
\end{tabular}

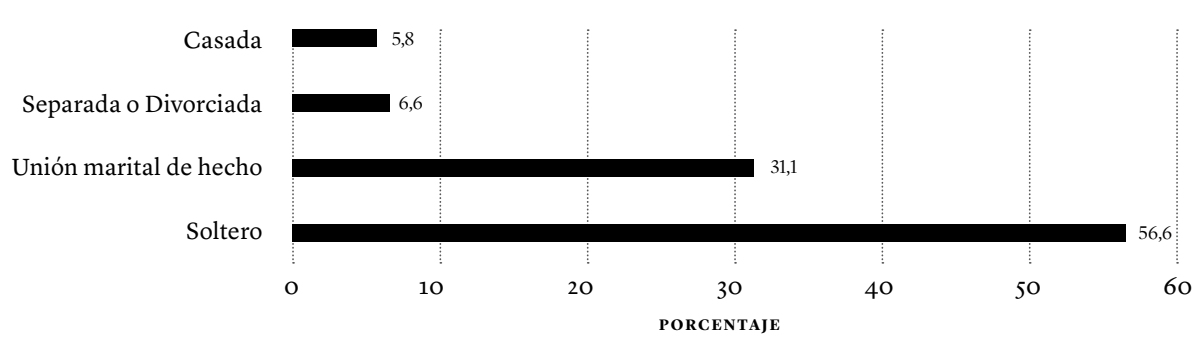


libertad que tenía la condición de cabeza de familia es significativamente más alto que el promedio nacional de jefatura femenina del hogar (40,9\%) (Departamento Administrativo Nacional de Estadística [DANE], 2018b).

El $85 \%$ de las mujeres encuestadas reportaron que son madres, en promedio tienen 2,7 hijos. El $46 \%$ tiene hijos menores de 11 años, y $15 \%$, hijos menores de 4 años. Algunos estudios indican que las madres, en comparación con otras mujeres, son desproporcionalmente más pobres, porque este hecho, simultáneamente, reduce los ingresos y aumenta las necesidades, especialmente por la responsabilidad de proveer a los hijos (Becker, 2000)․

$\mathrm{El}_{73} \%$ de las mujeres entrevistadas vivía con sus hijos antes de ser detenida; $54 \%$ eran las cuidadoras principales de sus hijos, y solo $4,2 \%$ reportó que los padres de sus hijos tenían este rol (Figura 6). En contraste, solo el 13,1 \% de los hombres internos encuestados eran los cuidadores principales de sus hijos antes de la detención, y el $60,9 \%$ señaló que la madre era la encargada de su cuidado.

FIGURA 6 $\quad$ Principal encargado del cuidado de los hijos antes de la detención

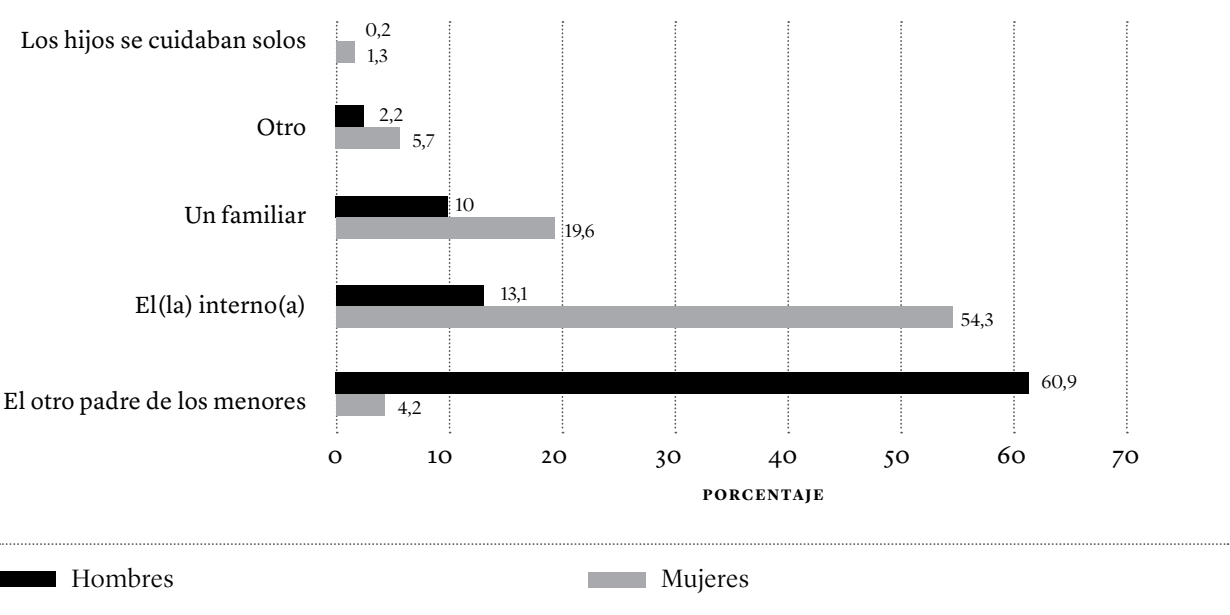

Fuente: encuesta proyecto "Mujeres y prisión en Colombia”. N=455 condenadas y 458 condenados con hijos. No incluye NS/NR

7. Análisis estadísticos han mostrado que la maternidad tiende a reducir los ingresos de las mujeres (Folbre, 1994). 
Estos datos confirman que la distribución social del cuidado es inequitativa, ya que este trabajo está asignado mayormente a las mujeres. Esta situación se evidencia en la Encuesta Nacional de Uso del Tiempo 2016-2017. Por ejemplo, la participación de las mujeres y los hombres en las actividades de suministro de alimentos a miembros del hogar se estimó en 74,4 \% y 24,9\%, respectivamente. Las mujeres dedican diariamente el doble del tiempo que los hombres a estas actividades ( 2 horas y 3 minutos vs. 58 minutos) (DANE, 2018a).

La división inequitativa del trabajo de cuidado está relacionada con el género. El cuidado se ha considerado como una característica femenina, la cual se transmite de generación en generación a través del rol de las madres como cuidadoras principales (Chodorow, 1999). La cantidad desproporcionada de trabajo de cuidado que desarrollan las mujeres y su devaluación perpetúan su desigualdad en la casa y el trabajo. Además, esta realidad puede tener diversos impactos en sus vidas, tales como: generar empobrecimiento económico (Jaramillo-Sierra; Anzola-Rodríguez, 2018), dificultar el acceso a la educación (Jaramillo-Sierra; Anzola-Rodríguez, 2018; Okin, 1989), obstaculizar el ingreso al mercado laboral o limitar sus elecciones laborales (Jaramillo-Sierra; Anzola-Rodríguez, 2018). Por ejemplo, las mujeres pueden llegar a evitar dedicarse a carreras demandantes o preferir trabajos de medio tiempo (Brody, 1981; Folbre, 1994; Okin, 1989).

\section{Historia laboral de las mujeres antes de la prisión y la informalidad}

La historia laboral de las mujeres encuestadas en la EPMPC se enmarca en un contexto de exclusión y discriminación en el mercado laboral (Alviar-García; Jaramillo-Sierra, 2012; Bernat-Díaz, 2007; Fernández, 2006; Hoyos; Ñopo; Peña, 2010; Organización para la Cooperación y el Desarrollo Económicos [OCDE], 2017).

A nivel mundial, entre 1995 y 2015, la tasa de participación de las mujeres en la fuerza de trabajo se redujo de 52,4\% a 49,6\%. Mientras que la probabilidad de que las mujeres participen en el mercado laboral sigue siendo menor que la de los hombres, en 27 puntos porcentuales. Muchas mujeres que trabajan siguen encontrándose en ocupaciones informales, trabajos a tiempo parcial y con baja remuneración. Para superar la brecha salarial se requerirían setenta años. La situación laboral de las mujeres impacta desfavorablemente su cobertura en protección social, sobre todo en sistemas contributivos donde las prestaciones dependen enteramente de las contribuciones que se realicen al sistema(como en el caso colombiano), lo cual las priva de prestaciones económicas tales como un subsidio durante la maternidad y una pensión de vejez o invalidez (Oficina Internacional del Trabajo [OIT], 2016).

En el contexto colombiano, los datos del DANE (2018c) sobre el mercado laboral en el primer semestre de 2018 muestran que la tasa global de participación fue 
74,8 \% para los hombres y 53,6 \% para las mujeres; la tasa de ocupación fue 69,4 \% para los hombres y 47,1 \% para las mujeres; y la tasa de desempleo fue $7,3 \%$ para los hombres y $12 \%$ para las mujeres, siendo esta tasa 1,6 veces más alta en mujeres que en hombres. Cabe resaltar que las diferencias entre las tasas de desempleo de hombres y mujeres son más amplias en niveles educativos más bajos (Figura 7).

FIGURA 7 $\mid$ Tasa de desempleo según nivel educativo y sexo

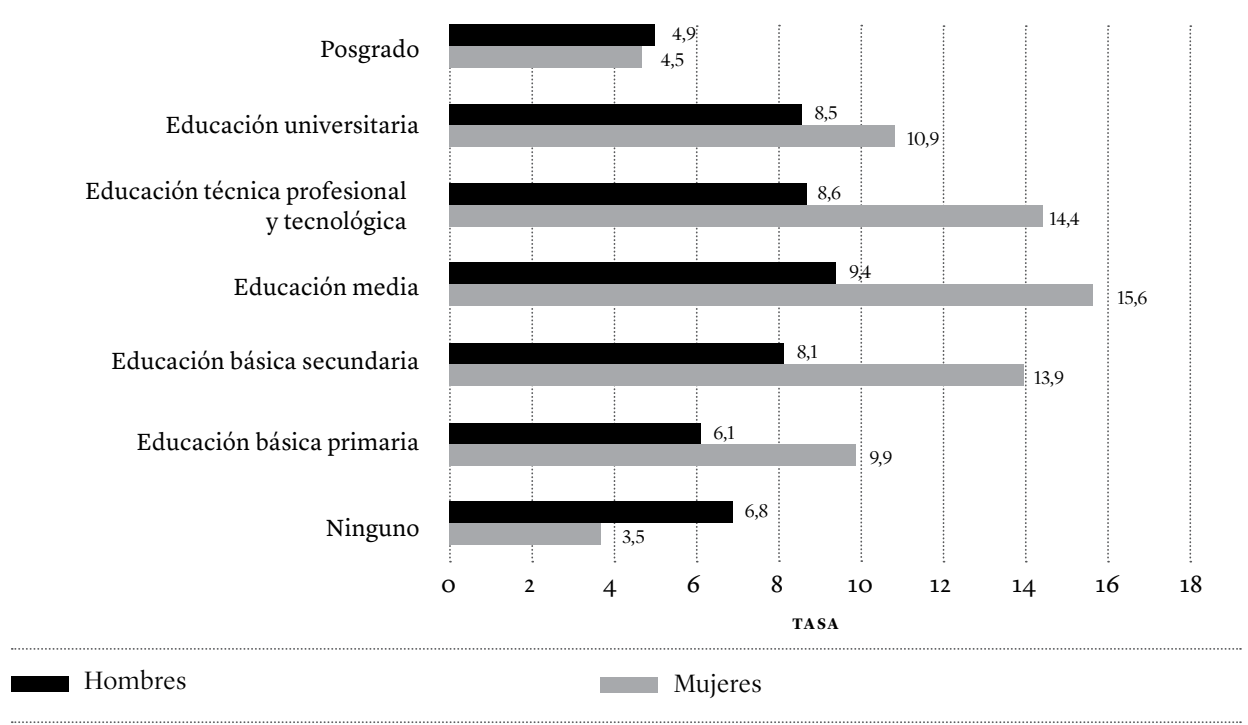

Fuente: DANE. Gran Encuesta Integrada de Hogares, Boletín técnico, 12.04.2018

Adicionalmente, en el mercado laboral se presenta una brecha salarial que favorece a los hombres, la cual ha sido estimada, aproximadamente, en $44 \%$ (CEDE, 2011). Algunos estudios han concluido que esta brecha se explica, principalmente, por las diferencias entre las remuneraciones que están asociadas a la discriminación de las mujeres (Fernández, 2006; Vélez; Winter, 1992).

De acuerdo con los datos del DANE (2018c) sobre el mercado laboral en el primer trimestre de 2018, la posición ocupacional de mayor participación para las mujeres en Colombia fue trabajadora por cuenta propia (40,1\%). Esta categoría ocupacional se asocia con situaciones de informalidad ${ }^{8}$. Adicionalmente, $6 \%$ de las mujeres era

8. El concepto de informalidad permite la aproximación a ciertos sectores a través de su cualificación. Si bien ha tenido una larga evolución desde la década de los setenta, momento en el que se comenzó a emplear este término, usualmente se refiere a aquellas formas de empleo que se encuentran al margen 
trabajadora familiar sin remuneración; es decir, estas mujeres se encontraban fuera del derecho laboral (DANE, 2018c).

Teniendo en cuenta que la relación de empleo estándar (caracterizada por ser tiempo completo, todo el año y con horarios poco flexibles) no es fácilmente compatible con las responsabilidades de cuidado, las mujeres tienden a tener trabajos precarios (Crompton, 2002; Fudge, 2014). Así, son más proclives a trabajar en el sector informal, el cual se caracteriza por remuneraciones menores, condiciones de trabajo de baja calidad, inestabilidad laboral y ausencia de seguridad social (CEPAL, 2018; OIT, 2015). De hecho, algunas de estas mujeres pueden encontrar en el sector informal la única alternativa para generar ingresos, teniendo en cuenta sus bajos niveles educativos, su limitada experiencia laboral y la falta de oportunidades en el mercado laboral formal (Rico de Alonso, 2006). Asimismo, las responsabilidades de cuidado pueden empujar a las mujeres hacia el sector informal, ya que esta es una alternativa que les permite armonizar más fácilmente el trabajo de cuidado con las tareas productivas, debido a su flexibilidad (Brody, 1981; Cárdenas; Mejía, 2007; Jaramillo-Sierra; Anzola-Rodríguez, 2018).

La brecha de género en el empleo también implica que las mujeres tengan un acceso limitado a la protección social, lo cual genera una disparidad entre hombres y mujeres en materia de cobertura de esta prestación. Por ello, la falta de protección social en la vejez afecta primordialmente a las mujeres (CEPAL, 2018; OIT, 2016).

En este contexto de subordinación de las mujeres en el mercado laboral, 73,1 \% de las mujeres entrevistadas en la EPMPC tenía un trabajo antes de la detención ${ }^{9}$. La posición ocupacional más frecuente era empleada (31,1\%). De otro lado, un alto porcentaje de mujeres se concentraba en labores por cuenta propia, que se caracterizan por la informalidad. Por ejemplo, el 19,3\% era independiente; 10,9\%, comerciante; y 9,6 \%, vendedora ambulante. Asimismo, el 13,9\% se dedicaba a actividades delictivas (Figura 8). Estos datos indican que un alto porcentaje de mujeres se encontraba en la informalidad, tanto en la legal como en la economía del delito (Caicedo, 2017).

del conjunto de derechos sociolaborales definidos en la legislación nacional (Oficina Internacional del Trabajo, 2016).

9. Tener un trabajo no está necesariamente asociado con la formalización o cumplimiento de la reglamentación laboral y de seguridad social, ya que existen trabajos remunerados que son informales debido a que no se benefician de ninguna seguridad social o laboral (ej.: asalariados informales, trabajadores por comisión, trabajadores ocasionales, trabajadores temporales, entre otros) (Bacchetta; Ernst; Bustamante, 2009). En la Figura 8 se detallan las ocupaciones principales reportadas por las mujeres encuestadas, algunas de estas pertenecientes al sector informal de la economía. 
Un porcentaje significativo desempeñaba ocupaciones tradicionalmente feminizadas, como ama de casa $(14,8 \%$ ) y trabajo doméstico (7,7 \%) (Figura 8). Uno de los problemas de los trabajos feminizados es su devaluación, pues se consideran de menor importancia y generan ingresos económicos inferiores o, incluso, no se prevé su compensación económica (Blumrosen, 1978; Chamallas, 2000). Todo lo anterior afecta la independencia económica de las mujeres que se dedican a este tipo de actividades.

FIGURA 8 Ocupación principal antes de ingresar al centro penitenciario

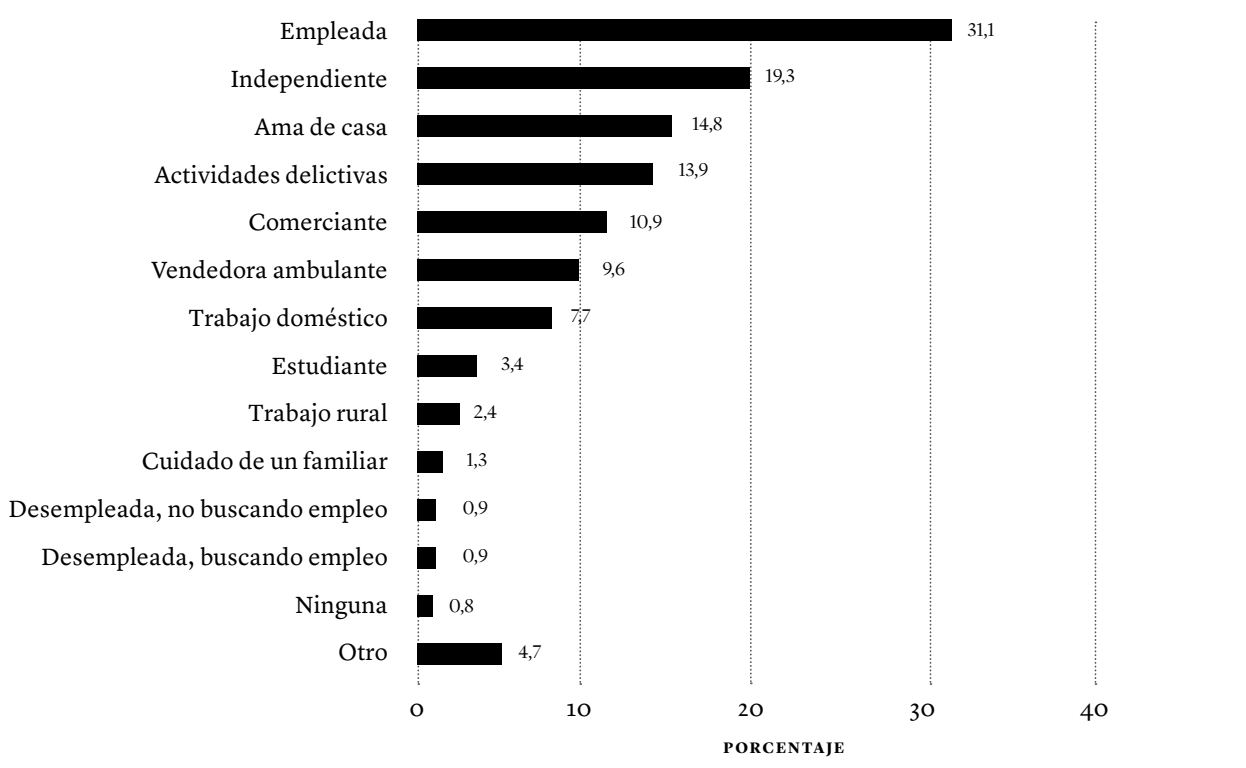

Fuente: encuesta proyecto "Mujeres y prisión en Colombia". N=533. Pregunta de múltiple respuesta, por ello el porcentaje puede superar el 100\%

En síntesis, las mujeres privadas de la libertad, antes de la detención, tenían la responsabilidad económica exclusiva de su hogar; estaban a cargo de varios hijos (entre otros dependientes); recibían ingresos que, en un alto porcentaje, eran inferiores al salario mínimo; vivían las consecuencias de un mercado laboral discriminatorio, y desempeñaban trabajos precarios e informales que se caracterizaban por su baja remuneración y bajo reconocimiento. Estos datos coinciden con los hallazgos de otros estudios sobre mujeres privadas de la libertad en Colombia (Ariza; Iturralde, 2015; Caicedo, 2017; Cruz et al., 2016; Advocacy for Human Rights in 
the Americas [WOLA]; International Drug Policy Consortium [IDPC]; Dejusticia; Inter-American Commission of Women [CIM]; Organización de los Estados Americanos [OEA], 2016).

\section{Perfil delictivo: delitos asociados a razones económicas}

De acuerdo con los datos del INPEC, los tres delitos con la proporción más alta por los que las mujeres se encuentran en prisión son: tráfico, fabricación o porte de estupefacientes $(45,2 \%)$; concierto para delinquir $(28,7 \%)$, y hurto $(17,4 \%$ ) (Figura 9). Estos datos confirman que los principales delitos que cometen las mujeres están relacionados con drogas o con la propiedad.

La criminología feminista ha demostrado que el género influye en la trayectoria hacia el delito y los tipos de delitos que cometen hombres y mujeres. Es menos probable que las mujeres cometan delitos violentos y es más probable que ejecuten delitos de drogas o contra la propiedad; a diferencia de los hombres, quienes tienen una mayor probabilidad de cometer delitos violentos y que representen un alto riesgo para la comunidad (Belknap, 2015; Bloom et al., 2003; Chesney-Lind; Pasko, 2013).

Un gran porcentaje de mujeres privadas de la libertad se encuentra en prisión por tráfico, fabricación o porte de estupefacientes, siguiendo una tendencia global. Algunos estudios han evidenciado la sobrerrepresentación de las mujeres en la población privada de la libertad por este tipo de actividades delictivas (Ariza; Iturralde, 2015; Corda, 2010; Cruz et al., 2016; Uprimny; Guzmán, 2010; WOLA et al., 2016).

\section{\begin{tabular}{l|l} 
FIGURA 9 & $\begin{array}{l}\text { Tipo de delitos por los que las mujeres y los hombres se encuentran } \\
\text { privados de la libertad a junio de } 2018\end{array}$
\end{tabular}}

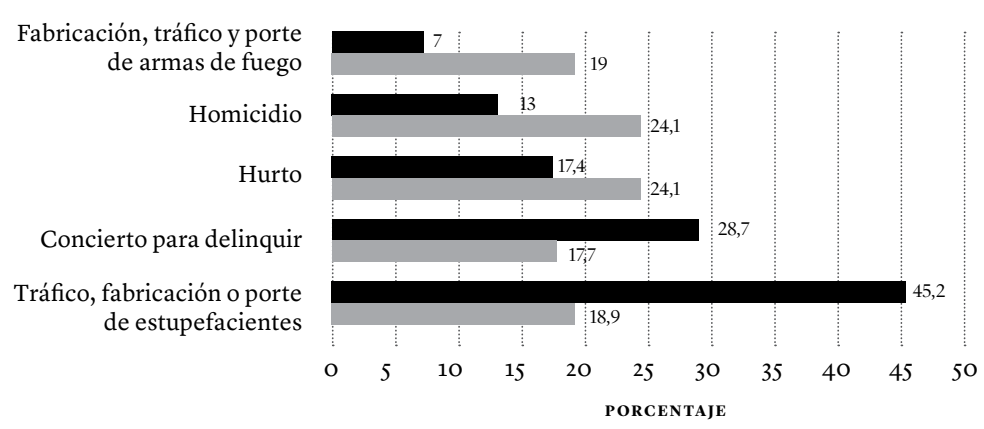


Las mujeres entrevistadas en la EPMPC reportaron que el motivo principal por el que cometieron el delito fue conseguir dinero (53,4\%) (Figura 10), y esto podría estar asociado a sus condiciones de vulnerabilidad social y económica. Importa resaltar que la actividad delictiva de las mujeres en América Latina se relaciona, principalmente, con la "criminalidad de pobreza” (Casas-Becerra, 2010).

FIGURA 10 $\quad$ Razones para cometer el delito por el que se encuentran detenidas

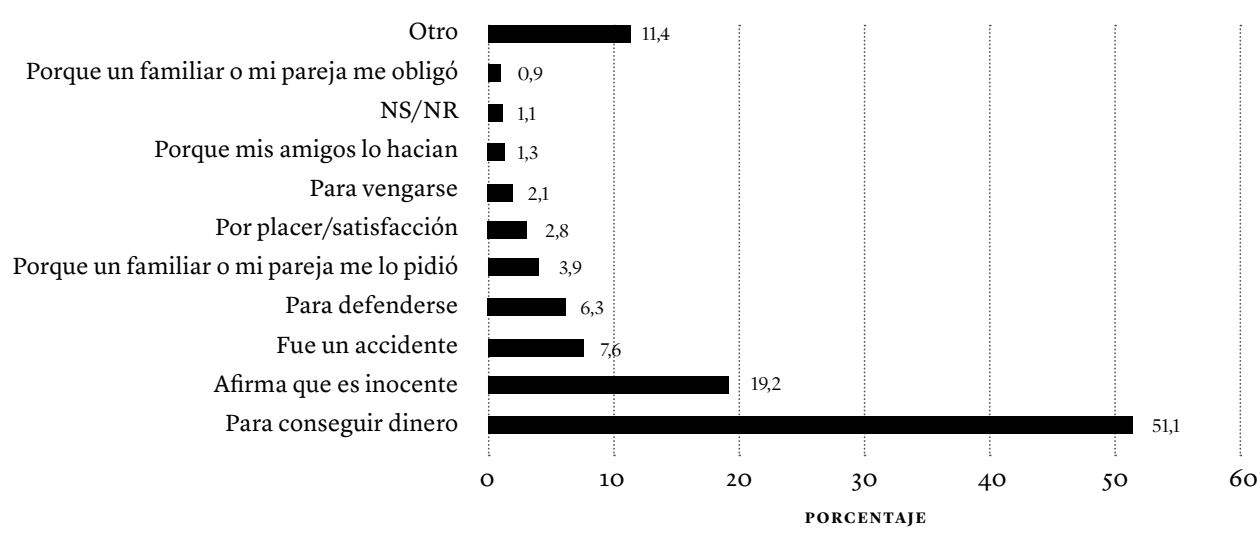

Fuente: encuesta proyecto "Mujeres y prisión en Colombia". $\mathrm{N}=528$. Pregunta de múltiple respuesta, por ello el porcentaje puede superar el $100 \%$

Algunos estudios han señalado que, en Colombia y otros países de América Latina, las dificultades para encontrar un empleo estable y la necesidad de cumplir con el rol de cabeza de familia pueden contribuir a que las mujeres entren en conflicto con la ley (Caicedo, 2017; Cruz et al., 2016; Giacomello, 2013; Ramos, 2003).

\section{Mujeres privadas de la libertad e interseccionalidad}

La criminología y las teorías de la prisión durante mucho tiempo han analizado el rol de la clase y la pobreza en el delito, el sistema penal y las prisiones (Garland, 2001; Rusche; Dinwiddie, 1978). A su vez, la criminología feminista ha argumentado que esos análisis asumían que la prisión era masculina, y ocultaban que el delito y las dinámicas de castigo también están formadas por el género. Esta literatura ha mostrado cómo el género importa en relación con la trayectoria hacia el delito y la manera en que el sistema de justicia penal responde a los infractores (Belknap, 2015; Chesney-Lind; Pasko, 2013). Durante las últimas décadas, ha surgido la intersecciona- 
lidad como marco conceptual que permite evidenciar las maneras en que interactúan múltiples categorías de identidad como género, raza y clase. La interseccionalidad evidencia cómo interactúan múltiples sistemas de poder y opresión (Crenshaw, 1991).

Los datos sobre el perfil socioeconómico de las mujeres privadas de la libertad presentados muestran que la mayoría de ellas experimentan una situación de marginalidad múltiple; pues sus historias personales están influenciadas por la intersección entre género y bajo estatus socioeconómico ${ }^{10}$. Como se ha mencionado anteriormente, estas mujeres tenían la responsabilidad económica exclusiva de su hogar, eran las cuidadoras principales de sus hijos u otros dependientes, recibían ingresos que en un alto porcentaje eran inferiores al salario mínimo, y desempeñaban trabajos precarios e informales.

Mujeres y hombres con el mismo nivel socioeconómico pueden compartir algunas características, pero las mujeres tienen unas circunstancias de vida específicas asociadas al género que hacen que su experiencia sea diferente. Las mujeres han experimentado discriminación basada en la jerarquía de género y son las principales cuidadoras de sus hijos o dependientes (Bloom et al., 2003; Covington; Bloom, 2003). A partir de los roles de género femenino y masculino, las estructuras de familia y trabajo forman un ciclo de vulnerabilidad que condiciona la vida y las elecciones de las mujeres. La posición desigual en la casa interactúa con la posición desigual en el lugar de trabajo (Okin, 1989).

Adicionalmente, las mujeres y los hombres tienen historias personales y caminos diferentes hacia el delito. De igual manera, suelen cometer tipos de delitos diferentes, pues es menos probable que las mujeres estén involucradas en delitos violentos y más probable que cometan delitos de drogas y contra la propiedad (Belknap, 2015; Bloom et al., 2003; Casas-Becerra, 2010; Chesney-Lind; Pasko, 2013; Covington; Bloom, 2003).

La Corte Constitucional ha señalado que las mujeres experimentan impactos diferenciados en la prisión:

La violencia y la discriminación en contra de las mujeres tienen unas repercusiones concretas -a las que no suele prestársele suficiente atención- cuando ellas entran en contacto con el sistema penitenciario. No hay que hilar muy delgado para recordar que, en un marco como ese, están expuestas a situaciones que aumentan exponencialmente su vulnerabilidad, con un impacto claramente diferenciado. Tampoco, que las mujeres reclusas tienen, en dicha esfera de privación de su libertad, unas necesidades especiales

10. En este texto no se presentan datos sobre raza ni se explora cómo esta interactúa con otros rasgos, ya que pocas mujeres encuestadas reportaron pertenecer a grupos étnicos (negra, mulata o afrocolombiana: 7,1 \%; indígena: 4,7 \%; ROM-gitana: 0,2 \%, y raizal del Archipiélago de San Andrés y Providencia) y, por ello, no se cuenta con datos suficientes para realizar este análisis. 
que suplir y unos problemas concretos que enfrentar, desde los ámbitos más básicos y vitales (Corte Constitucional, T- 276, 2018) .

Algunos autores han argumentado que la prisión reproduce y refuerza los órdenes sociales de clase y género (Ariza; Iturralde, 2015; Caicedo, 2017; Iturralde, 2011; Rusche; Dinwiddie, 1978). Así, las formas de opresión y discriminación de las mujeres se agravan durante la reclusión y después de quedar en libertad, teniendo en cuenta sus condiciones de marginalidad y sus responsabilidades de cuidado (Ariza; Iturralde, 2015). En consecuencia, las condiciones de vulnerabilidad social y económica se profundizan.

Teniendo en cuenta que en el caso de la mayoría de las mujeres privadas de la libertad interactúan múltiples categorías de identidad-bajo nivel socioeconómico y género-, las estrategias de intervención en el sistema penal y el sistema penitenciario deben buscar abordar estas intersecciones para mejorar los resultados.

\section{El trabajo en prisión}

En la sección anterior, se evidenció que las mujeres privadas de la libertad, antes de ingresar a la prisión, se caracterizaban por ser cabeza de familia, tener una situación económica desfavorable, contar con bajos niveles educativos, y desempeñarse en trabajos informales o tradicionalmente feminizados -escasamente remunerados y no reconocidos-.

Al momento de ingresar a prisión, se esperaría que las mujeres pudieran acceder a programas laborales que transformaran sus perspectivas para el momento de retornar a la libertad, con el fin de mejorar sus posibilidades de reinserción social. Uno de los objetivos del sistema de justicia penal y del penitenciario es ofrecer programas, intervenciones y servicios para reducir la reincidencia. Para lograr este objetivo, es clave tener en cuenta el perfil de las mujeres, así como las diferencias entre hombres y mujeres infractores, en tanto estas condiciones afectan la capacidad del sistema para enfrentar los factores asociados con la trayectoria hacia el delito (Covington; Bloom, 2003).

Las actividades de trabajo en los centros penitenciarios, junto con el estudio y la enseñanza, son parte del tratamiento penitenciario, el cual tiene como fin preparar a la persona para el regreso a la vida en libertad y lograr el fin resocializador de la pena (Congreso de Colombia, Ley 65, 1993). De acuerdo con información suministrada por el INPEC, a junio de 2019, 48 854 personas privadas de la libertad se encontraban vinculadas a actividades laborales. De estas actividades, las que tenían un mayor número de personas vinculadas eran artesanales y servicios (Tabla 1). 


\begin{tabular}{|c|c|}
\hline TABLA 1 & $\begin{array}{l}\text { Actividades laborales y porcentaje de la población privada de la libertad } \\
\text { vinculada a junio de 2019 }\end{array}$ \\
\hline Proyecto & PPL \\
\hline Artesanales & $68,5 \%$ \\
\hline Servicios & $24,4 \%$ \\
Enseñanza & $3,8 \%$ \\
\hline Industria & $2,7 \%$ \\
\hline Agrícola y pecuario & $0,6 \%$ \\
\hline
\end{tabular}

Fuente: INPEC (2019)

El Ministerio de Justicia y del Derecho, con base en datos suministrados por el Departamento Nacional de Planeación, señaló que el 2,5 \% de las actividades laborales se desarrollaban con recursos de terceros, bajo la modalidad de administración indirecta; el $11 \%$ de la oferta laboral estaba a cargo del INPEC, y el 86,5\% de las actividades eran financiadas, directamente, por los reclusos (Congreso de Colombia, Proyecto de Ley Número 14, 2017).

Algunos estudios han encontrado que los recursos del INPEC son insuficientes para ofrecer programas laborales y educativos para la población penitenciaria (Iturralde, 2011; Ramírez; Parra-Gallego, 2016). Adicionalmente, el Ministerio de Justicia y del Derecho (2014) ha resaltado los siguientes problemas relacionados con las actividades laborales y educativas: la formación de los funcionarios, los altos índices de desocupación de los internos y la falta de elementos para realizar las actividades. La precariedad y la falta de recursos para las actividades laborales afecta tanto a hombres como a mujeres privadas de la libertad, pero esta situación se ve exacerbada frente a ellas, debido a sus historias personales y sus condiciones específicas, antes de la detención y durante la prisión (Carlen; Worrall, 2012).

En esta sección, se analizará la percepción de las mujeres encuestadas frente a los programas o actividades laborales en los centros penitenciarios. En primer lugar, se expondrá que los programas ofrecidos a las mujeres privadas de la libertad reproducen los estereotipos de género. En segundo lugar, se argumentará que la regulación del trabajo en prisión permite que la labor de muchas mujeres privadas de la libertad se encuentre al margen del derecho laboral. 


\section{Programas o actividades laborales en los centros penitenciarios y estereotipos de género}

El 56,7 \% de las participantes en la EPMPC manifestó que ha participado en programas o actividades laborales en la prisión ${ }^{11}$. Una limitación de estos programas $\mathrm{o}$ actividades es la reproducción de los estereotipos de género. La Figura 11 muestra que los programas laborales en los que han participado principalmente son: programas artesanales $(58,62 \%)$ y aseo $(21,32 \%)$.

FIGURA 11 | Tipo de programas o actividades laborales en los que ha participado

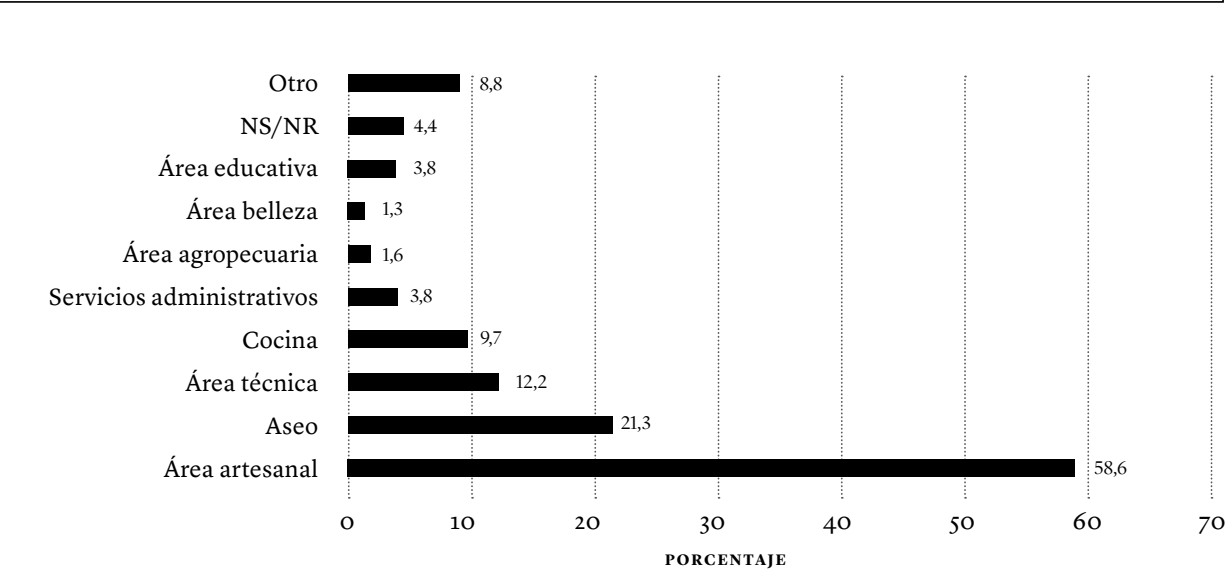

Fuente: encuesta proyecto "Mujeres y prisión en Colombia”. N=319. Pregunta de múltiple respuesta, por ello el porcentaje puede superar el $100 \%$

Asimismo, las encuestadas indicaron que las principales habilidades adquiridas en la prisión son artesanía, costura, belleza o peluquería, pintura o decoración, y cocina (Figura 12).

Aunque los programas del área artesanal también son predominantes para los hombres privados de la libertad en Colombia, la oferta de programas laborales afecta de manera específica a las mujeres, ya que se centran en actividades que se consideran femeninas, y en el desarrollo de habilidades y aptitudes propias de las mujeres (Ariza; Iturralde, 2017; Carlen; Worrall, 2012). Estas ocupaciones que reproducen o refuerzan los roles de género no transforman las habilidades de las mujeres, y contribuyen a perpetuar su subordinación económica. Cabe reiterar que 
FIGURA 12 $\mid$ Tipo de habilidades adquiridas durante la condena

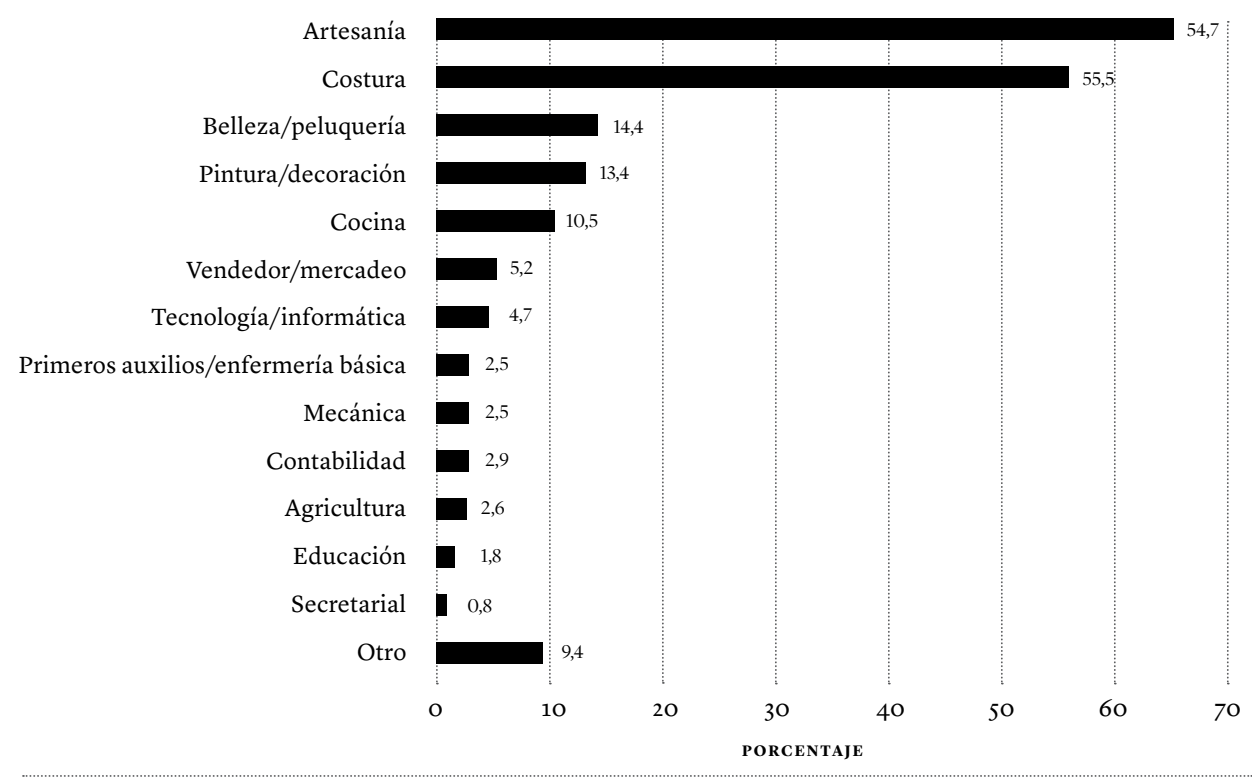

Fuente: encuesta proyecto "Mujeres y prisión en Colombia". N=382. Pregunta de múltiple respuesta, por ello el porcentaje puede superar el 100 \%

los trabajos feminizados se caracterizan por su baja remuneración y reconocimiento. Por ello, concentrarse en actividades como la elaboración de manualidades o actividades de aseo y cocina puede ocasionar que no se transformen significativamente las condiciones sociales, económicas y laborales de las mujeres cuando retornen a la comunidad.

En este sentido, el 28,4 \% de las participantes manifestó que no creía probable que las actividades o programas laborales las ayudaran a encontrar empleo al quedar en libertad ${ }^{12}$. De este subgrupo de mujeres ${ }^{13}, 28,6 \%$ consideraba que ya tenía las habilidades antes de ingresar a prisión, es decir, las actividades laborales ofrecidas se identificaban con las desempeñadas antes de ser detenidas. Además, el 29,9\% consideraba que las actividades no eran relevantes para el mercado laboral. De hecho, el $67,5 \%$ de las mujeres que ya había estado en prisión indicó que las habilidades que adquirieron en los programas laborales o educativos, en su anterior detención, 
no fueron útiles para obtener ingresos económicos ni encontrar empleo al salir de la cárcel la última vez ${ }^{14}$.

Al parecer, los programas laborales no consideran la necesidad de transformar las habilidades laborales de las reclusas de cara a una historia laboral informal y precarizada. Por el contrario, los centros penitenciarios reflejan los roles tradicionales de género, contribuyendo a preservar la situación de vulnerabilidad social y económica de las mujeres (Añaños-Bedriñana; García-Vita, 2017).

Ante la pregunta sobre temas o áreas de interés para la implementación de nuevos programas en la institución penitenciaria, un alto porcentaje de mujeres seleccionó actividades tradicionalmente femeninas, reproduciendo o aceptando los estereotipos de género (arte/manualidades, peluquería/belleza, costura/diseño de modas). Simultáneamente, un alto porcentaje de ellas escogió áreas que se alejan de lo típicamente femenino (computadores/tecnología, idiomas, economía/administración/negocios) (Figura 13).

\section{Mujeres privadas de la libertad en Colombia como trabajadoras al margen del mercado y el derecho laboral}

\section{Caracterización del trabajo en prisión y la aplicación del derecho laboral}

En la literatura sobre el trabajo en prisión se debaten dos cuestiones: cómo se caracteriza este tipo de trabajo y, según la manera como se rotula esta relación, si las leyes laborales aplican. A partir de estas dos cuestiones, el trabajo en prisión se ha caracterizado de dos maneras: como trabajo rehabilitador y como trabajo productivo.

En primer lugar, el trabajo en los centros de reclusión se ha categorizado como trabajo rehabilitador, debido a que se considera diferente y separado del libre (Clark; Parker, 1974), y por ello, se excluye de la categoría legal de empleo (Zatz, 2009). El carácter penal implica la ausencia de una relación de mercado y conlleva que la relación sea penológica y no pecuniaria ${ }^{15}$ (Zatz, 2008; 2009). El trabajo de los internos es considerado como un medio para que aprendan disciplina, hábitos y habilidades ocupacionales (Clark; Parker, 1974). Tiene, entonces, un carácter rehabilitador que contribuye a reducir las probabilidades de reincidencia (Zatz, 2009).

Esta caracterización del trabajo en prisión por el derecho permite la disparidad entre los trabajadores reclusos y los libres, ya que a los internos se les niegan algunos derechos laborales básicos que tienen los otros (Clark; Parker, 1974). Por ejemplo, el

14. $\mathrm{N}=4 \mathrm{O}$.

15. Ver United States Court of Appeals (1993). 


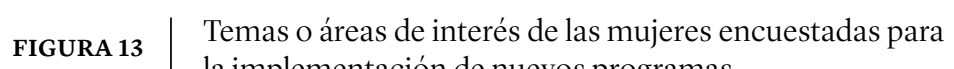

la implementación de nuevos programas

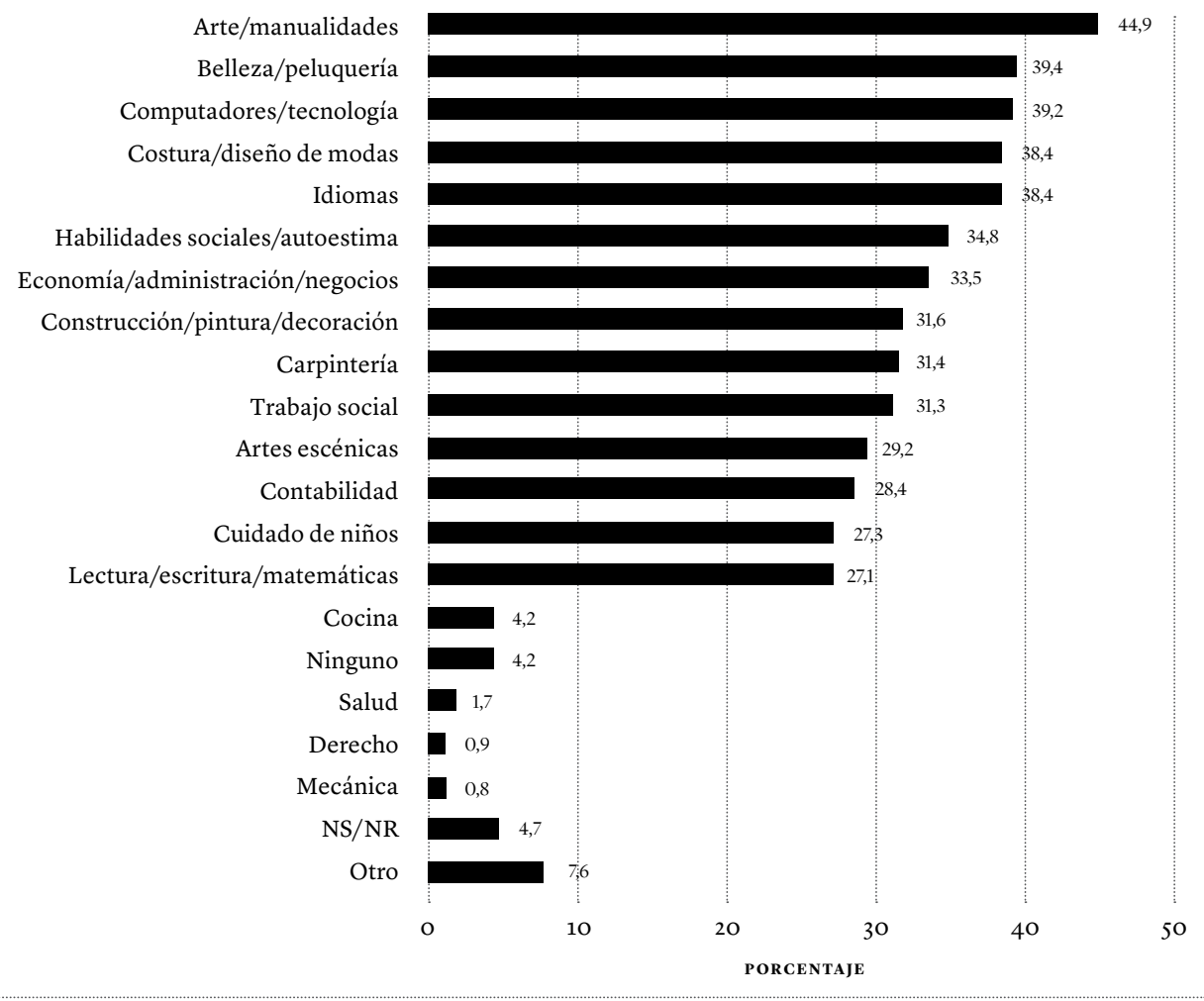

Fuente: encuesta proyecto “Mujeres y prisión en Colombia”. Base: 536 mujeres condenadas. Pregunta de múltiple respuesta, por ello el porcentaje puede superar el $100 \%$

reconocimiento del derecho a un salario mínimo usualmente encuentra una fuerte resistencia ${ }^{16}$ (Clark; Parker, 1974). En consecuencia, esta caracterización ubica a los internos fuera del alcance de la protección del derecho laboral.

Algunas de las racionalidades que fundamentan las limitaciones a los derechos laborales son: la naturaleza del trabajo penitenciario y su carácter rehabilitador; la carga presupuestal para el Estado que implicarían los costos asociados a una vinculación laboral con todos los beneficios legales; posibles reclamos de actores sociales frente a otorgar condiciones "privilegiadas" a las personas privadas de la libertad; y 
el principio de menor elegibilidad, según el cual las condiciones de la prisión deben ser peores que las condiciones de vida de los ciudadanos de la clase más baja que cumplen la ley, para que las personas prefieran abstenerse de la realización de una conducta criminal (Rusche; Dinwiddie, 1978). Este último punto fundamenta la imposibilidad de equiparar las condiciones laborales de la prisión con las del trabajo libre, pues si las condiciones ofrecidas son mejores o iguales, el obrero precarizado podría tener incentivos para cometer un delito, con el objetivo de cubrir sus necesidades básicas (Ariza-Higuera, 2017) ${ }^{17}$.

En segundo lugar, el trabajo penitenciario se ha caracterizado como trabajo productivo, en tanto tiene características similares a las relaciones de empleo, tales como la remuneración y la supervisión (Zatz, 2009). La labor en prisión puede ser representada como trabajo en el mercado, ya que constituye un intercambio económico de una actividad valiosa por un pago monetario. En muchos casos, su labor produce bienes y servicios que son vendidos fuera de la prisión (Zatz, 2009). Teniendo en cuenta lo anterior, el trabajo en prisión, además de penológico, sería pecuniario $^{18}$. En consecuencia, el trabajo en prisión y el trabajo libre se deberían tratar de la misma manera (Clark; Parker, 1974).

\section{Caracterización del trabajo en prisión y aplicación del derecho laboral en Colombia}

La normatividad penitenciaria y carcelaria colombiana establece que las funciones principales del trabajo en prisión son la resocialización y la redención de la pena. Uno de los objetivos del trabajo es preparar a las internas para la vida en libertad (Congreso de Colombia, Ley 65, 1993). Las reglas y la jurisprudencia constitucional han aplicado las dos caracterizaciones del trabajo penitenciario expuestas, a través de las dos modalidades del trabajo previstas: la administración indirecta y la directa (INPEC, 1995: Art. 61), como se explica a continuación.

En la administración indirecta se representa como trabajo productivo, pues el establecimiento penitenciario pone a disposición de personas jurídicas o naturales recursos físicos para que realicen actividades productivas, vinculando la mano de obra de los internos (INPEC, 1995: Art. 61). La persona natural o jurídica se encarga de la compensación o pago a las internas. El trabajo en prisión se integra de manera clara en las instituciones y relaciones del mercado.

17. En algunos países, los programas disponibles para los internos han generado indignación pública. Ver Gray, Mays y Stohr (1995).

18. Ver Opinión Disidente del Juez Norris (United States Court of Appeals, 1993). 
Esta modalidad ha sido regulada con base en una perspectiva de trabajo productivo, donde se requiere la voluntad del interno, el pago de un salario mínimo y el cumplimiento de las mismas condiciones de protección del trabajo libre regido por el Código Sustantivo del Trabajo y demás regulaciones laborales (INPEC, 1995: Art.62; Corte Constitucional, T-429, 2010). El Ministerio de Justicia y del Derecho, con base en datos suministrados por el Departamento Nacional de Planeación, indicó que solo el 2,5\% de las actividades laborales en los centros penitenciarios se desarrollaban con recursos de terceros, bajo la modalidad de administración indirecta (Congreso de Colombia, Proyecto de Ley Número 14, 2017).

Por el contrario, en la administración directa se representa como trabajo rehabilitador, donde el establecimiento penitenciario pone a disposición de los internos los recursos productivos necesarios para el desarrollo de actividades industriales, agropecuarias y de servicios, y controla el desarrollo de las mismas (INPEC, 1995: Art. 61). La mayor parte de las actividades que el INPEC considera idóneas para la redención de pena se desarrollan bajo esta modalidad (Congreso de Colombia, Proyecto de Ley Número 14, 2017).

Debido a que esta modalidad se ha regulado desde una perspectiva de trabajo rehabilitador, no existe un contrato de trabajo y las condiciones y los derechos no son los mismos del trabajo libre. En las labores en prisión bajo administración directa se garantizan unas condiciones mínimas como protección en salud y riesgos laborales, y una remuneración equitativa (que no es igual a un salario mínimo), teniendo en cuenta los estándares de la OIT (Reyes; Garzón, 2015; Corte Constitucional, T-429, 2010). Todo lo anterior conlleva a que la actividad de estas mujeres quede afuera del contrato de trabajo y esté al margen del derecho laboral. Así las cosas, en las prisiones colombianas el alcance del derecho laboral y del contrato de trabajo depende del rol del centro penitenciario en la administración de las actividades y de la participación de un tercero que ofrece los recursos para el proceso productivo.

El Ministerio de Justicia y del Derecho propuso una reconceptualización del trabajo penitenciario a través de un proyecto de ley que fue archivado. Según la propuesta, la categoría "trabajo penitenciario" se reservaría para las actividades desarrolladas bajo administración indirecta y para servicios ejecutados a favor del INPEC que sobrepasen las actividades relacionadas con la pena de prisión (ej.: mantenimiento de infraestructura). Es decir, actividades como monitores de aseo o de educación no constituirían trabajo penitenciario ni deberían ser remuneradas, ya que se considerarían como directamente asociadas a la ejecución de la pena de prisión (Congreso de Colombia, Proyecto de Ley Número 14, 2017). 


\section{El trabajo penitenciario desde una perspectiva rehabilitadora al margen del derecho laboral}

A continuación, vamos a analizar el trabajo penitenciario bajo administración directa regulado con base en una perspectiva rehabilitadora. Desde esta perspectiva, la prisión es un espacio de excepción a la aplicación de la norma laboral vinculada al contrato de trabajo, pues se considera que el penitenciario no tiene la misma finalidad del trabajo libre, que es satisfacer el mínimo vital del trabajador y su núcleo familiar. De acuerdo con la Corte Constitucional:

El trabajo penitenciario no tiene por finalidad satisfacer el mínimo vital del recluso, sino que es eminentemente terapéutico al igual que un medio para redimir la pena (...) el trabajo penitenciario no deviene de un contrato laboral sino de una relación de derecho público que surge como consecuencia de la pena (Corte Constitucional, T-429, 2010).

La Corte Constitucional (2010), además, ha establecido las siguientes diferencias entre el trabajo libre y el trabajo en prisión:

- Es voluntario.

- El trabajador vende su fuerza laboral en el mercado.

- Es una relación eminentemente económica.
- Es obligatorio.

- No existe contrato de trabajo.

- Es una relación de derecho público que surge como consecuencia de la pena de prisión.

- Algunos derechos laborales no cobijan a los internos.

- La remuneración debe ser equitativa, no debe ser igual a un salario mínimo y no tiene efectos prestacionales.

- Existe una intromisión en la destinación del salario (por ejemplo, prohibición de usarlo en el centro penitenciario).

La regulación del trabajo en prisión como rehabilitador o terapéutico genera que este esté al margen del derecho laboral. Los efectos principales de este régimen son: los ingresos pueden ser inferiores al salario mínimo legal, y los aportes a seguridad social son voluntarios. Estos dos efectos parecieran generar una situación de continuidad en la desprotección que experimentaba la mayoría de las mujeres privadas de la libertad antes de su detención, debido a la informalidad laboral. 


\title{
Ingresos percibidos por el trabajo en prisión
}

El ordenamiento jurídico permite recibir ingresos inferiores al salario mínimo legal mensual vigente por el trabajo en prisión bajo administración directa. La Corte Constitucional ha señalado que:

\begin{abstract}
No sobra indicar que el trabajo penitenciario no tiene por finalidad satisfacer el mínimo vital del recluso, sino que es eminentemente terapéutico al igual que un medio para redimir la pena. Por lo tanto, su remuneración equitativa, salvo en el caso de los reclusos que trabajen para particulares -y que, como se verá, corresponde a la administración indirecta- no tiene por qué ser igual a un salario mínimo (Corte Constitucional, T-429, 2010).
\end{abstract}

En la misma línea, el Decreto 1758 de 2015 establece:

ARTÍCULO 2.2.1.10.1.4. Remuneración. La remuneración percibida por las personas privadas de la libertad en razón a los convenios de resocialización y trabajo penitenciario, no constituye salario y no tiene los efectos prestacionales derivados del mismo.

La compensación para las personas privadas de la libertad no debe ser igual a un salario mínimo, pero debe ser equitativa. La remuneración no puede ser desproporcionadamente baja y conllevar la precarización salarial, ya que esto implicaría la explotación de los internos (Corte Constitucional, T-429, 2010). De acuerdo con la Corte Constitucional, la figura de la remuneración equitativa y la resistencia a garantizar un salario mínimo se fundamentan en las restricciones presupuestales del Estado. Se argumenta que las bonificaciones muy altas podrían causar dificultades presupuestales para que se generen suficientes oportunidades laborales para los internos, especialmente en un escenario con altas tasas de hacinamiento (Corte Constitucional, T-429, 2010). Cabe mencionar que el pago de un salario mínimo legal mensual vigente, el reconocimiento de prestaciones sociales y las cotizaciones al Sistema de Seguridad Social Integral podrían ascender a un monto aproximado de $\$ 1120852$ mensuales $^{19}$.

El Ministerio de Justicia y del Derecho ha indicado que los internos reciben una bonificación aproximada del $10 \%$ del salario mínimo legal, por actividades como monitores de aseo y de educación, y bibliotecarios (Congreso de Colombia, Proyecto de Ley Número 14, 2017).

El Comité de América Latina y el Caribe para la Defensa de los Derechos de la Mujer (2008) ha señalado que es problemático que la remuneración que las mujeres reciben se encuentre muy por debajo de la que ofrece el mercado laboral fuera de la

19. Esta cifra responde a una liquidación tentativa, tomando el salario mínimo legal mensual vigente para el año 2019, que asciende a $\$ 828116$. 
cárcel, ya que muchas de ellas tienen la condición de cabeza de familia. Los ingresos bajos impactan su rol de cuidadoras en el hogar y las relaciones con sus hijos, especialmente en los casos en que siguen siendo la única o principal fuente de ingresos de sus hogares (Centro de Estudios Legales y Sociales [CELS], 2011).

Es de resaltar que muchas mujeres privadas de la libertad siguen teniendo un rol de proveedoras para satisfacer las necesidades de sus dependientes. De acuerdo con los resultados de la EPMPC, mientras estas mujeres cumplen su condena, sus hijos menores de 18 años viven principalmente con la abuela (43,7\%), con otros familiares $(17,4 \%)$ o con el padre $(21,1 \%)$. Usualmente, estos cuidadores también tienen un nivel socioeconómico bajo, por lo que encargarse del cuidado les genera cargas desproporcionadas (investigadora de una organización de defensa de los derechos de las mujeres, comunicación personal, 17.04.2018).

Muchas mujeres privadas de la libertad son sostenedoras de la economía familiar, pero se encuentran en una situación de precariedad laboral reforzada en el contexto de la prisión (Añaños-Bedriñana; García-Vita, 2017). En estas circunstancias, es importante repensar la concepción del trabajo penitenciario como un simple medio terapéutico o de redención de pena. En realidad, el trabajo de muchas de estas mujeres cumple una función desconocida por la Corte Constitucional: garantizar el mínimo vital de sus dependientes.

\section{Sistema de Seguridad Social: protección a la vejez}

El régimen sobre personas privadas de la libertad no contempla la obligación de cotización al subsistema de seguridad social en pensiones. El Decreto 1758 de 2015 se refiere a la protección a la vejez en los siguientes términos:

\footnotetext{
ARTÍCULO 2.2.1.10.2.2. Protección a la vejez. Las personas privadas de la libertad menores de 65 años, que así lo soliciten, podrán ser afiliadas al Sistema Flexible de Protección para la Vejez constituido por los Beneficios Económicos Periódicos. El Ministerio del Trabajo determinará anualmente el monto del aporte correspondiente, el cual deberá ser descontado de la remuneración percibida por la persona privada de la libertad. El INPEC coordinará el giro de los recursos a la entidad a la cual se afilie a la persona privada de la libertad.
}

Esta disposición brinda una protección voluntaria a través de los Beneficios Económicos Periódicos que garantizan ingresos, pero nunca iguales al salario mínimo legal mensual vigente. Así las cosas, durante la estancia en prisión que tiene lugar en la edad laboral de las mujeres no se garantiza una cotización para alcanzar una pensión en la edad vulnerable. Esto acentúa las posibilidades de precariedad 
de la población femenina de la tercera edad que ha estado recluida en un centro penitenciario.

La mayoría de las mujeres privadas de la libertad no tenía la opción de contribuir para una pensión en sus trabajos antes de la detención, y en la prisión se preservan y agravan sus problemas de cobertura en protección social. Cabe recordar que la falta de esta protección en la vejez afecta primordialmente a las mujeres, debido a la brecha de género en el empleo (CEPAL, 2018; OIT, 2016).

En síntesis, la regulación del trabajo en prisión con base en una perspectiva rehabilitadora excluye a muchas mujeres privadas de la libertad del derecho laboral y les niega algunos de los derechos mínimos del trabajo libre. El alcance limitado del derecho laboral frente a estas mujeres tiene un impacto negativo en sus derechos y en el rol como proveedoras que mantienen algunas de ellas en sus hogares desde la prisión. Teniendo en cuenta lo anterior, es importante repensar el alcance del derecho laboral en la prisión, y la distinción entre el trabajo libre y el penitenciario, así como reflexionar sobre el trato diferencial que se establece para las actividades bajo administración directa e indirecta.

\section{Expectativas de las mujeres privadas de la libertad frente al mercado laboral, en el momento de retornar a la comunidad}

La transición a la comunidad de las mujeres que retornan a la libertad implica múltiples retos. De ellos, los principales que las encuestadas creen que van a enfrentar en el futuro son los obstáculos para conseguir un trabajo (53,5\%), las dificultades económicas (48,3\%) y la estigmatización o rechazo social (Figura 14).

Es de aclarar que tanto los hombres como las mujeres que regresan a la comunidad enfrentan retos para conseguir trabajo, lograr estabilidad económica y encontrar vivienda. Sin embargo, las mujeres enfrentan circunstancias específicas debido al género; por ejemplo, el rol de ser la cuidadora principal de los hijos y la discriminación en el mercado laboral.

La mayoría de las mujeres en prisión tienen hijos y suelen ser la principales encargadas de su cuidado, muchas de ellas quieren asumir la atención de sus hijos al quedar en libertad, mientras los padres de los hijos usualmente no están a cargo de su cuidado durante la detención ni ofrecen ningún aporte económico, y los familiares que custodian los hijos durante la detención con frecuencia esperan que la madre asuma esta responsabilidad inmediatamente es liberada (Bloom et al., 2003). Por ello, los retos económicos y laborales que enfrentan estas mujeres al retornar 
\begin{tabular}{l|l} 
FIGURA 14 & $\begin{array}{l}\text { ¿Cuáles cree que son las principales dificultades que va a enfrentar después } \\
\text { de quedar en libertad? }\end{array}$
\end{tabular}

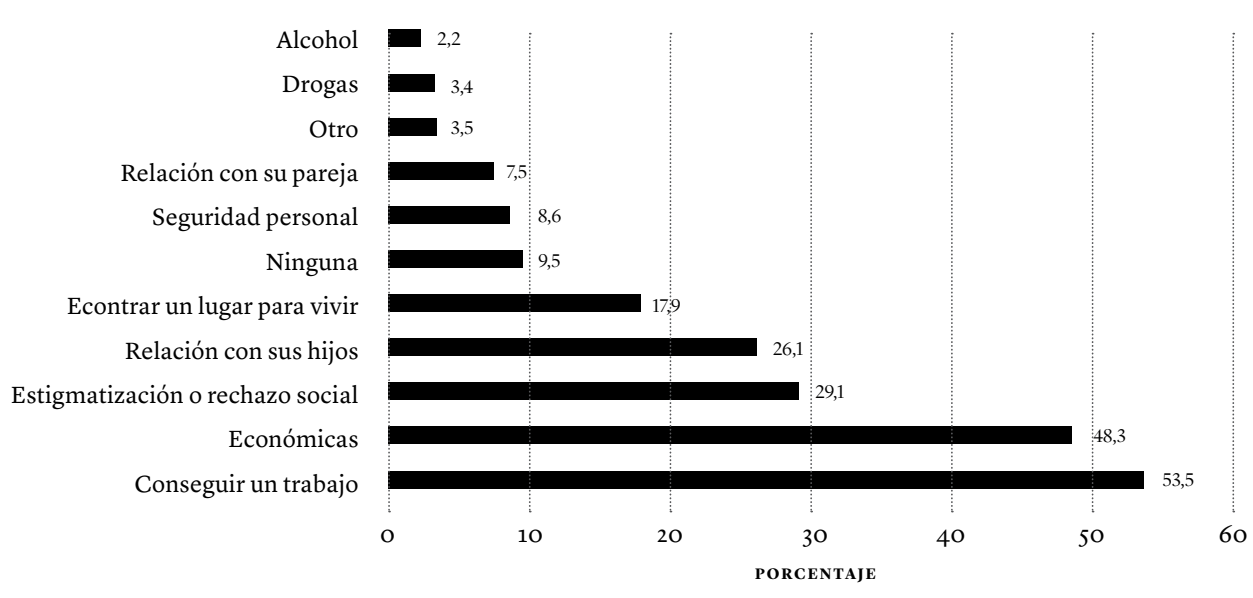

Fuente: encuesta proyecto "Mujeres y prisión en Colombia". Base: 536 mujeres condenadas. Pregunta de respuesta múltiple. No incluye NS/NR

a la comunidad incluyen las necesidades de sus hijos, lo cual representa una carga adicional para ellas (Bloom et al., 2003; Brown; Melchior; Huba, 1999; Covington; Bloom, 2003). El caso de los hombres privados de la libertad es distinto, ya que la mayoría de ellos no suelen ser los cuidadores principales de sus hijos y estos, usualmente, viven con la madre durante la condena del padre.

Las pospenadas usualmente enfrentan diversos obstáculos para encontrar un empleo (pospenada, comunicación personal, 26.04.2018). En primer lugar, los asociados al perfil de las mujeres; por ejemplo, sus bajos niveles educativos, su limitada experiencia profesional y la falta de habilidades relevantes para el mercado laboral (Cruz et al., 2016; WOLA et al., 2016). Es de reiterar que estas habilidades no se ven transformadas durante la prisión, debido a las limitaciones de los programas laborales ofrecidos (Ariza; Iturralde, 2015). En segundo lugar, los obstáculos asociados a la discriminación de las mujeres en el contexto laboral y a un mercado productivo que se caracteriza por la informalidad preponderantemente femenina (Alviar-García; Jaramillo-Sierra, 2012; Bernat-Díaz, 2007; Fernández, 2006; Hoyos et al., 2010; OCDE, 2017).

En tercer lugar, los obstáculos asociados a los antecedentes penales que agravan las dificultades de acceso a un mercado laboral precario para las mujeres. En Colom- 
bia, este historial no se cancela y es fácilmente accesible por potenciales empleadores o cualquier persona a través de la consulta en línea (Presidencia de la República de Colombia, Decreto 19, 2012: Art. 94). Algunos estudios han mostrado que, en Colombia y otros países, las personas que han tenido una condena experimentan discriminación laboral, debido a que los antecedentes penales contribuyen a reducir las posibilidades de conseguir un trabajo (Blumstein; Nakamura, 2009; Damaska, 1968; Escobar-Vélez, 2018; Larrauri; Jacobs, 2011; Naylor; Paterson; Pittard, 2008; Pager; Western; Sugie, 2009).

Si se considera la función que cumple el trabajo en las sociedades actuales como una de las principales formas de vínculo social, autorrealización y subsistencia, los efectos de la prisión en las posibilidades laborales de estas mujeres están afectando su reinserción en la sociedad (Méda, 1998). Al obstaculizar el ingreso al mundo laboral de las pospenadas, el castigo trasciende la prisión y perpetúa la exclusión social. Un estudio sobre mujeres y encarcelamiento en América Latina concluyó que: "una vez terminan su condena y son puestas en libertad, sus antecedentes penales perjudican la posibilidad de encontrar un empleo decente y legal, lo cual perpetúa el círculo vicioso de exclusión social y encarcelamiento" (WOLA et al., 2016: 10).

\section{Conclusiones}

Los datos de la EPMPC muestran que el perfil de la mayoría de las mujeres privadas de la libertad en Colombia se caracteriza por una situación de marginalidad múltiple, debido a la intersección entre género y bajo estatus socioeconómico. Esta condición conlleva vulnerabilidad social y económica. En su mayoría, estas mujeres son madres, eran cabeza de familia, vivían con sus hijos y eran las responsables principales de su cuidado, antes de la detención. Ellas experimentan precariedad económica y, simultáneamente, tienen necesidades derivadas de su rol de proveedoras y cuidadoras.

La situación laboral de la mayoría de mujeres privadas de la libertad antes de la detención se caracterizaba por la informalidad, posiblemente debido a sus bajos niveles educativos, su experiencia laboral limitada y sus responsabilidades exclusivas de cuidado. En la prisión, algunas de ellas participan en programas o actividades laborales que reflejan los estereotipos de lo femenino y los roles de género. Dichos programas no transforman las habilidades y oportunidades de las mujeres en el mercado laboral. Adicionalmente, la regulación sobre el trabajo penitenciario reproduce y exacerba las condiciones del empleo informal y precario para muchas mujeres en prisión, lo cual impacta negativamente sus derechos, los ingresos que perciben y su 
protección en el sistema de seguridad social. Esto es especialmente problemático para aquellas que, desde la prisión, mantienen el rol de proveedoras en sus hogares.

Al retornar a la libertad, la mayoría de estas mujeres enfrenta retos económicos y laborales que incluyen la necesidad de proveer a los hijos, lo cual implica una carga adicional. Los datos sugieren que enfrentan múltiples obstáculos para conseguir un trabajo estable y remunerado. Uno de los mayores impedimentos para las mujeres que han estado en prisión son los antecedentes penales. Teniendo en cuenta las dificultades para ingresar al mercado laboral, las altas tasas de informalidad de este y los retos económicos derivados del rol de cuidadora principal de los hijos, es posible que las mujeres se vinculen al sector informal, tanto al legal como a la economía del delito.

En síntesis, las mujeres experimentan un continuo de marginalidad múltiple y vulnerabilidad social y económica. La prisión refuerza las formas de desigualdad atadas a su género y bajo nivel socioeconómico durante la reclusión y después de retornar a la comunidad. Estas condiciones de vulnerabilidad social y económica incluyen la precariedad laboral. El trabajo de muchas mujeres privadas de la libertad está al margen del ordenamiento laboral -antes, durante y después de la prisión-. El Código Sustantivo del Trabajo construye la identidad de trabajador asociada al contrato de trabajo y determina quién puede reclamar derechos laborales. Las actividades desempeñadas por la mayoría de las mujeres encuestadas dentro y fuera de la prisión no están representadas por la idea de trabajador de este código.

El entrenamiento en la prisión para un trabajo que será productivo y útil al quedar en libertad es una necesidad apremiante de las mujeres, porque puede ofrecer sustento para ellas y sus hijos y, con ello, contribuir a romper el continuo de marginalidad y vulnerabilidad económica. Adicionalmente, teniendo en cuenta que muchas mujeres reportaron que delinquieron por razones económicas y los principales delitos por los que se encuentran detenidas han sido catalogados como "criminalidad de pobreza", mejorar sus habilidades para el mercado laboral puede contribuir a reducir la reincidencia.

Con el fin de mejorar los resultados del sistema penal y el sistema penitenciario, en términos de propiciar la resocialización y reducir la reincidencia, es clave ofrecer programas, intervenciones y servicios que tengan en cuenta el perfil de las mujeres y su situación de marginalidad múltiple. Estos programas contribuirían a enfrentar los factores asociados con la trayectoria hacia el delito de las mujeres infractoras. 


\section{Referencias}

Albin, Einat (2012). From 'Domestic Servant' to 'Domestic Worker'. En Challenging the Legal Boundaries of Work Regulation. Recuperado de https://papers.ssrn.com/sol3/papers. cfm?abstract_id=2240245

Alviar-García, Helena; Jaramillo-Sierra, Isabel Cristina (2012). Feminismo y crítica jurídica: el análisis distributivo como alternativa crítica al legalismo liberal. Bogotá: Siglo del Hombre.

American Psychological Association (2007). Report of the APA Task Force on Socioeconomic Status. Washington, DC: American Psychological Association.

Añaños-Bedriñana, Fanny; García-Vita, María del Mar (2017). Definiendo la prisionalización en reclusas: un análisis socioeducativo desde el desarrollo humano. Recuperado de http:// congreso.us.es/pedsoc17/papers/linea\%203/PDF/L3O3.pdf

Aristizábal, Edith; Ríos-García, Ana Liliana; Del Pozo-Serrano, Francisco José (2016). Salud mental, género, educación social en mujeres reclusas del Centro de Rehabilitación Femenino El Buen Pastor de Barranquilla, Colombia (2015-2016). Revista Científica Salud Uninorte, 32(2), 256-267.

Ariza-Higuera, Libardo José (2017). El trabajo como castigo, el trabajo como derecho del condenado. En Derecho laboral para el nuevo tiempo: construcción conjunta (pp. 147-165), editado por Ana María Muñoz Segura. Bogotá: Universidad de los Andes.

Ariza-Higuera, Libardo José; Ángel-Botero, Carolina (2015). En el corazón del Buen Pastor. La apropiación del discurso de los derechos humanos en el contexto penitenciario colombiano. Antípoda, 23, 45-64.

Ariza-Higuera, Libardo José; Iturralde, Manuel (2015). Una perspectiva general sobre mujeres y prisiones en América Latina y Colombia. Derecho Público, 35. http://dx.doi.org/10.15425/ redepub.35.2015.10

Ariza-Higuera, Libardo José; Iturralde, Manuel (2017). Mujer, crimen y castigo penitenciario. Politica criminal, 12(24), 731-753.

Bacchetta, Marc; Ernst, Ekkehard; Bustamante, Juana (2009). La globalización y el empleo informal en los paises en desarrollo. Recuperado de https://www.wto.org/spanish/res_s/ booksp_s/jobs_devel_countries_s.pdf

Becker, Mary (200o). Caring the Children and Caretakers. Chicago-Kent Law Review, 76(3), 1495-1540.

Belknap, Joanne (2015). The Invisible Woman: Gender, Crime, and Justice. Cengage Learning: Colorado. 
Bernat-Díaz, Luisa Fernanda (2007). ¿Quiénes son las mujeres discriminadas?: enfoque distributivo de las diferencias salariales por género. Borradores de Economía y Finanzas, 13, 2-31.

Bloom, Barbara; Owen, Barbara; Covington, Stephanie (2003). Gender-Responsive Strategies: Research, Practice, and Guiding Principles for Women Offenders. Recuperado de https://info. nicic.gov/nicrp/system/files/o18017.pdf

Blumrosen, Ruth (1978). Wage Discrimination, Job Segregation, and the Title VII of the Civil Rights Act of 1964. University of Michigan Journal of Law Reform, 12(3), 397-502.

Blumstein, Alfred; Nakamura, Kiminori (2009). Redemption in the Presence of Widespread Criminal Background Checks. Criminology, 47(2), 327-359.

Briceño-Donn, Marcela (2006). Mujeres y prisión en Colombia: análisis desde una perspectiva de derechos humanos y de género. Recuperado de http://corteidh.or.cr/tablas/24314.pdf

Brody, Elaine (1981). "Women in the Middle" and Family Help to Older People. The Gerontologist, 21(5), 471-480. Recuperado de https://academic.oup.com/gerontologist/article-abstract $/ 21 / 5 / 471 / 631614$ ?redirectedFrom=fulltext

Brown, Vivian; Melchior, Lisa; Huba, George (1999). Level of Burden among Women Diagnosed with Severe Mental Illness and Substance Abuse. Journal of Psychoactive Drugs, 31(1), 31-40.

Busby, Nicole (2011). A Right to Care?: Unpaid Work in European Employment Law. Oxford: Oxford University Press.

Caicedo, Luz Piedad (2017). Mujeres en prisión por delitos de drogas: espejo de las fisuras del desarrollo. Bogotá: Corporación Humanas Colombia.

Cárdenas, Mauricio; Mejía, Carolina (2007). Informalidad en Colombia: nueva evidencia. Fedesarrollo Documentos de Trabajo, 35, 2-43.

Carlen, Pat; Worrall, Anne (2012). Analysing Women's Imprisonment. Routledge: Michigan.

Casas-Becerra, Lidia (2010). Introducción a los problemas de género en la Justicia Penal en América Latina. Santiago: Centro de Estudios de Justicia de las Américas.

Centro de Estudios Legales y Sociales (2011). Mujeres en prisión. Los alcances del castigo. Buenos Aires: Siglo XXI.

Centro de Estudios sobre Desarrollo Económico (2011). Colombia en movimiento: un análisis descriptivo basado en la Encuesta Longitudinal Colombiana de la Universidad de los Andes ELCA. Recuperado de https://elca-colombiaenmovimiento.uniandes.edu.co/libro/ColombiaEnMovimiento-Completo.pdf

Chamallas, Martha (2000). Deepening the Legal Understanding of Bias: On Devaluation and Biased Prototypes. Southern California Law Review, 74, 747-806. 
Chesney-Lind, Meda; Pasko, Lisa (2013). The Female Offender: Girls, Women, and Crime. SAGE: Hawaii.

Chodorow, Nancy (1999). The Reproduction of Mothering: Psychoanalysis and the Sociology of Gender. Berkeley: University of California Press.

Clark, Leroy; Parker, Gwendolyn (1974). The Labor Law Problems of the Prisoner. Rutgers L. Rev., 28, 840-860.

Comisión Económica para América Latina y el Caribe (s. f.). Índice de feminidad de la pobreza extrema y de la pobreza según área geográfica. Recuperado de http://interwp.cepal.org/ sisgen/ConsultaIntegrada.asp?idIndicador $=1694$ \&idioma $=\mathrm{e}$

Comisión Económica para América Latina y el Caribe (2018). Panorama Social de América Latina 2017. Santiago: Naciones Unidas.

Comité de América Latina y el Caribe para la Defensa de los Derechos de la Mujer (2008). Violencia contra mujeres privadas de la libertad. Sistematización regional Argentina, Brasil, Chile, Colombia, Paraguay y Uruguay. Recuperado de https://www.cladem.org/images/ pdfs/publicaciones/regionales/violencia/estudio-mujeres-privadas-libertad.pdf

Congreso de Colombia (19 de agosto de 1993). Ley 65 de 1993: Por la cual se expide el Código Penitenciario y Carcelario. Recuperado de http://www.secretariasenado.gov.co/senado/ basedoc/ley_oo65_1993.html

Congreso de Colombia (27 de julio de 2017). Exposición de motivos. Proyecto de Ley Número 14 de 2017: Por medio de la cual se fortalece la política criminal y penitenciaria en Colombia y se dictan otras disposiciones. Gaceta del Congreso, 602.

Corda, Alejandro (2010). Encarcelamientos por delitos relacionados con estupefacientes en Argentina. En Sistemas sobrecargados: Leyes de drogas y cárceles en América Latina (pp. 1120), editado por Pien Metaal; Coletta Youngers. Ámsterdam/Washington: Transnational Institute/Washington Office on Latin America.

Corte Constitucional (2010). Sentencia T-429/10. Recuperado de http://www.corteconstitucional.gov.co/relatoria/2010/t-429-10.htm

Corte Constitucional (2018). Sentencia T-267/18. Recuperado de http://www.corteconstitucional.gov.co/relatoria/2018/t-267-18.htm

Covington, Stephanie; Bloom, Barbara (2003). Gendered Justice: Women in the Criminal Justice System. En Gendered Justice: Addressing Female Offenders (pp. 3-23), editado por Barbara Bloom. Durham, NC: Carolina Academic Press.

Crenshaw, Kimberle (1991). Mapping the Margins: Intersectionality, Identity Politics, and Violence Against Women of Color. Stanford Law Review, 43(6), 1241-1299. 
Crompton, Rosemary (2002). Employment, Flexible Working and the Family. The British Journal of Sociology, 53(4), 537-558.

Cruz, Luis Felipe; Martínez-Osorio, Margarita; Chaparro-González, Nina; Uprimny-Yepes, Rodrigo; Chaparro-Hernández, Sergio (2016). Mujeres, políticas de drogasy encarcelamiento: una guía para la reforma de políticas en Colombia. Bogotá: Antropos.

Damaska, Mirjan (1968). Adverse Legal Consequences of Conviction and their Removal: A Comparative Study. Journal of Criminal Law and Criminology, 59(3), 347-360.

Departamento Administrativo Nacional de Estadística (2018a). Encuesta nacional de uso del tiempo 2016-2017. Recuperado de https://www.dane.gov.co/index.php/estadisticas-por-te$\mathrm{ma} /$ pobreza-y-condiciones-de-vida/encuesta-nacional-del-uso-del-tiempo-enut

Departamento Administrativo Nacional de Estadística (2018b). Resultados preliminares del Censo Nacional de Poblacióny Vivienda 2018. Recuperado de https://www.dane.gov.co/files/ censo2018/informacion-tecnica/resumen-2da-entrega-CNPV-preliminar.pdf

Departamento Administrativo Nacional de Estadística (2018c). Mercado laboral según sexo. Recuperado de https://www.dane.gov.co/index.php/estadisticas-por-tema/mercado-laboral/segun-sexo

Departamento Administrativo Nacional de Estadística (2018d). Gran Encuesta Integrada de Hogares. Recuperado de http://www.dane.gov.co/index.php/178-english/sociales/cultura/2921-gran-encuesta-integrada-de-hogares

Del Pozo-Serrano, Francisco José; Martínez-Idárraga, Jairo Alberto (2015). Retos del tratamiento penitenciario en Colombia: enfoque y acción diferencial de género desde la perspectiva internacional. Criminalidad, 57(1), 9-25.

Escobar-Vélez, Susana (2018). Los antecedentes penales como obstáculo a la reincorporación social. En Política criminal y abolicionismo, hacia una cultura restaurativa (pp. 493-528), editado por Marcela Gutiérrez; Ángela Marcela Olarte. Bogotá: Universidad Externado de Colombia.

Fernández, María del Pilar (2006). Determinantes del diferencial salarial por género en Colombia, 1997-2003. Revista Desarrollo y Sociedad, 58, 165-208.

Folbre, Nancy (1994). Who Pays for the Kids?: Gender and the Structures of Constraint. Routledge: Cambridge.

Fudge, Judy (2014). Feminist Reflections on the Scope of Labour Law: Domestic Work, Social Reproduction, and Jurisdiction. Feminist Legal Studies, 22(1), 1-23.

Garland, David (2001). The Culture of Control: Crime and Social Order in Contemporary Society. Oxford: Oxford University Press. 
Giacomello, Corina (2013). Mujeres, delitos de drogasy sistemas penitenciarios en América Latina. Recuperado de https://www.unodc.org/documents/congress/background-information/ NGO/IDPC/IDPC-Briefing-Paper_Women-in-Latin-America_SPANISH.pdf

Gray, Tara; Mays, Larry; Stohr, Mary (1995). Inmate Needs and Programming in Exclusively Women's Jails. The Prison Journal, 75(2), 186-202.

Hoyos, Alejandro; Nopo, Hugo; Peña, Ximena (2010). The Persistent Gender Earnings Gap in Colombia, 1994-2006. Documento CEDE, 007094.

Instituto Nacional Penitenciario y Carcelario (1995). Acuerdo 11 de 1995: Por el cual se expide el Reglamento General al cual se sujetarán los reglamentos internos de los Establecimientos Penitenciariosy Carcelarios. Recuperado de http://www.inpec.gov.co/documents/20143/44983/ ACUERDO++11+de+1995+y+ACUERDO+11+AGTo6+Mdfca+Acdo+11OCT9.pdf/ c46039b6-c163-7197-ef74-83db3da8568d

Instituto Nacional Penitenciario y Carcelario (2018). Estadisticas. Recuperado de http://www. inpec.gov.co/documents/20143/410518/6.+ESTADISTICAS+JUNIO+3O+DE+2018.xls/ 47ofiba7-4b5d-8d87-2b7d-oe98d7dcc5bc?version=1.0\&download=true

Iturralde, Manuel (2011). Prisiones y castigo en Colombia: la construcción de un orden social excluyente. En Los muros de la infamia: prisiones en Colombia y en América Latina (pp. 110195), editado por Manuel Iturralde; Libardo José Ariza-Higuera. Bogotá: Universidad de los Andes.

Jaramillo-Sierra, Isabel Cristina; Anzola-Rodríguez, Sergio Iván (2018). La batalla por los alimentos: El papel del derecho civil en la construcción del género y la desigualdad. Bogotá: Universidad de los Andes.

Larrauri, Elena; Jacobs, Jaimes (2011). Reinserción laboral y antecedentes penales. Revista Electrónica de Ciencia Penaly Criminología, 13(9), 1-25.

López-Barbosa, Nahyr; Castro-Jiménez, Miguel Ángel; Gamboa-Delgado, Edna Magaly; Vera-Cala, Lina María (2009). Prevalencia y determinantes de las infecciones vaginales en las mujeres recluidas en una cárcel colombiana. Revista Chilena de Obstetricia y Ginecología, 74(2), 77-82.

Méda, Dominique (1998). El trabajo: un valor en peligro de extinción. Barcelona: Gedisa.

Ministerio de Justicia y del Derecho (2014). Lineamientos para el fortalecimiento de la política penitenciaria en Colombia. Recuperado de https://www.academia.edu/35393544/Lineamientos_para_el_fortalecimiento_de_la_Pol\%C3\%ADtica_Penitenciaria_en_Colombia

Naylor, Bronwyn; Paterson, Moira; Pittard, Marilyn (2008). In the Shadow of a Criminal Record: Proposing a Just Model of Criminal Record Employment Checks. Melbourne University Law Review, 32, 171-197. 
Norza-Céspedes, Ervyn; González-Rojas, Andrea; Moscoso-Rojas, Manuel; González-Ramírez, Juan David (2012). Descripción de la criminalidad femenina en Colombia: factores de riesgo y motivación criminal. Criminalidad, 54(1), 339-357.

Observatorio de Igualdad de Género de América Latina y el Caribe (2017). Índice de feminidad en hogares pobres. Recuperado de https://oig.cepal.org/es/indicadores/indice-feminidad-hogares-pobres

Okin, Susan Moller (1989). Justice, Gender, and the Family. New York: Basic Books.

Organización Internacional del Trabajo (2015). Sector informal y las formas atípicas de empleo. Recuperado de https://www.ilo.org/actrav/areas/WCMS_DOC_ATR_ARE_INF_ES/lang-es/index.htm

Organización Internacional del Trabajo (2016). Las mujeres en el trabajo: tendencias de 2016. Ginebra: Oficina Internacional del Trabajo.

Organización para la Cooperación y el Desarrollo Económicos (2017). Estudios económicos de la OCDE en Colombia. Recuperado de http://www.oecd.org/eco/surveys/Colombia-2017-OECD-economic-survey-overview-spanish.pdf

Pager, Devah; Western, Bruce; Sugie, Naomi (2009). Sequencing Disadvantage: Barriers to Employment Facing Young Black and White Men with Criminal Records. The ANNALS of the American Academy of Political and Social Science, 623(1), 195-213. Recuperado de https:// www.ncbi.nlm.nih.gov/pmc/articles/PMC3583356/pdf/nihms-439026.pdf

Presidencia de la República de Colombia (10 de enero de 2012). Decreto 19 de 2010: Por el cual se dictan normas para suprimir o reformar regulaciones, procedimientos y trámites innecesarios existentes en la Administración Pública. Diario Oficial, 48308.

Presidencia de la República de Colombia (1 de septiembre de 2015). Decreto 1758 de 2015: Por el cual se adiciona al Título 1 de la Parte 2 del Libro 2 del Decreto 1069 de 2015, Decreto Único Reglamentario del Sector Justicia y del Derecho, un Capitulo 10 que regula las especiales condiciones de trabajo de las personas privadas de la libertad. Recuperado de https://www. funcionpublica.gov.co/eva/gestornormativo/norma.php?i=62961

Quejada-Pérez, Raúl; Yánez-Contreras, Martha; Cano-Hernández, Kelly (2014). Determinantes de la informalidad laboral: un análisis para Colombia. Investigación \& Desarrollo, 22(1), 126-145.

Ramírez, Alanis; Parra-Gallego, Germán (2016). Cárceles de la muerte: necropolítica y sistema carcelario en Colombia. Universitas Humanística, 82, 365-391.

Ramos, Patricia (2003). Diagnóstico de la situación de las mujeres encarceladas en Colombia. En Violencia contra las mujeres privadas de libertad en América Latina (pp.115-126), editado por Comisión de Derechos Humanos del Distrito Federal, editado por Comisión Mexicana 
de Defensa y Promoción de los Derechos Humanos; Fundación para el Debido Proceso Legal. México D. F.: Corunda.

Rico de Alonso, Ana (2006). Jefatura femenina, informalidad laboral y pobreza urbana en Colombia: expresiones de desigualdad social. En La persistencia de la desigualdad. Género, trabajo y pobreza en América Latina (pp. 177-198), editado por Gioconda Herrera. Quito: Flacso.

Rusche, Georg; Dinwiddie, Gerda (1978). Labor Market and Penal Sanction: Thoughts on the Sociology of Criminal Justice. Crime and Social Justice, 10, 2-8.

Sánchez-Mejía, Astrid; Rodríguez-Cely, Leonardo; Fondevila, Gustavo; Morad, Juliana (2018). Mujeres y prisión en Colombia: desafíos para la política criminal desde un enfoque de género. Recuperado de https://repository.javeriana.edu.co/handle/10554/41010?locale-attribute $=\mathrm{pt}$

Silbaugh, Katharine (1996). Turning Labor into Love: Housework and the Law. Northwestern University Law Review, 91, 1-86.

United States Court of Appeals (31 de agosto de 1992). Vanskike v. Peters, 974 F.2d 806 (7th Cir. 1992). Recuperado de https://casetext.com/case/vanskike-v-peters

United States Court of Appeals (4 de mayo de 1993). Hale v. Arizona, 993 F.2d 1387 (9th Cir. 1993). Recuperado de https://casetext.com/case/hale-v-state-of-ariz

Uprimny, Rodrigo; Guzmán, Diana Esther (2010). Políticas de droga y situación carcelaria en Colombia. En Sistemas sobrecargados: leyes de drogas y cárceles en América Latina (pp. 4050), editado por Pien Metaal; Coletta Youngers. Ámsterdam/Washington: Transnational Institute/Washington Office on Latin America.

Vélez, Eduardo; Winter, Carolyn (1992). Women's Labor Force Participation and Earnings in Colombia. En Case Studies on Women's Employment and Pay in Latin America (pp. 197-207), editado por George Psacharopoulos; Zafiris Tzannatos. Washington, DC: The World Bank.

WOLA; International Drug Policy Consortium; Dejusticia; Inter-American Commission of Women; Organización de los Estados Americanos (2016). Women, Drug Policies, and Incarceration: A Guide for Policy Reform in Latin America and the Caribbean. Recuperado de https://www.wola.org/wp-content/uploads/2016/o2/Women-Drug-Policies-and-Incarceration-Guide_Final.pdf

Zatz, Noah (2008). Working at the Boundaries of Markets: Prison Labor and the Economic dimenSion of Employment Relationships. Vanderbilt Law Review, 61, 857-958.

Zatz, Noah (2009). Prison Labor and the Paradox of Paid Nonmarket Work. En Economic Sociology of Work (pp. 369-398), editado por Nina Bandelj. Bingley: Emerald Group Publishing Limited. 